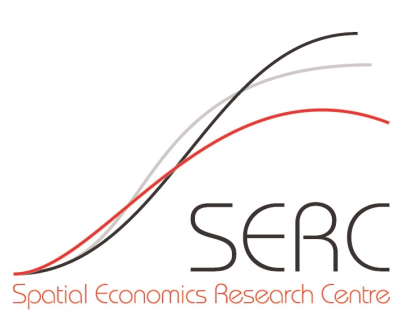

SERC DISCUSSION PAPER 83

\title{
Whether to Hire Local Contract Teachers? Trade-off Between Skills and Preferences in India
}

Sonja Fagernäs (Department of Economics, University of Sussex)

Panu Pelkonen (SERC, CEE Department of Economics, University of Sussex)

July 2011 
This work is part of the research programme of the independent UK Spatial Economics Research Centre funded by the Economic and Social Research Council (ESRC), Department for Business, Innovation and Skills (BIS), the Department for Communities and Local Government (CLG), and the Welsh Assembly Government. The support of the funders is acknowledged. The views expressed are those of the authors and do not represent the views of the funders.

(C) S. Fagernäs and P. Pelkonen, submitted 2011 


\section{Whether to Hire Local Contract Teachers? Trade-off Between Skills and Preferences in India \\ Sonja Fagernäs* \\ Panu Pelkonen**}

July 2011

* Department of Economics, University of Sussex

** SERC, CEE, Department of Economics, University of Sussex

Acknowledgements

The authors would like to thank STICERD, London School of Economics and Political Science, for funding this project. Invaluable advice and support was provided to us by the helpful staff of the Uttarakhand DIETs and Dr Navin Kabadwal of SCERT Uttarakhand. We would like to thank Kunwar Singh Rawat of SSA Uttarakhand, Professors Arun Mehta and K. Sudha Rao of NUEPA, Professor Mohammad Akhtar Siddiqui of NCTE, Professor A.K. Jalalluddin, as well as Gautam Malik of SCERT Punjab and staff at SCERT Himachal Pradesh for very useful discussions prior to collecting the data. The draft has benefited from comments from participants at the CEP/LSE Labour market seminar, the Indian Statistical Institute Annual Conference, QSS research seminar (Institute of Education) and the Sussex Economics Departmental Seminar. We are also particularly grateful to Paul Atherton, Victor Lavy, John Van Reenen, and Marcello Sartarelli for constructive comments and criticisms. 


\begin{abstract}
$\underline{\text { Abstract }}$
Whether to hire teachers locally on a contract basis, or via competitive examinations as government officials, is a major policy question in developing countries. We use a Discrete Choice Experiment to assess the job preferences of 700 future elementary school teachers in the state of Uttarakhand in India. The students have been selected using either competitive examination or from a pool of locally hired contract teachers. Skills in English, Arithmetic and Vocabulary are also tested. We find a trade-off between skills and preferences, as students hired using competitive examination have higher skills, but prefer posts in less remote regions.
\end{abstract}

Keywords: Discrete choice experiment, education, para-teachers, preferences, skills JEL Classifications: H75, J24, J41, J45 


\section{Introduction}

Improvements in health and education are of primary importance in enabling people to overcome poverty. However, there are great difficulties in providing good quality public services in remote areas in developing countries. One key problem relates to attracting and retaining educated personnel in these difficult locations. Various approaches have been experimented with to motivate qualified key personnel to work in remote locations (see e.g. WHO, 2006).

In India, recruitment decisions of teachers have traditionally been made at the state level and teachers have been recruited as civil servants on permanent contracts. However, the practice has been criticised for producing unmotivated teachers with little incentives, often absent as they choose to commute to their rural workplace from far (Sharma, 1999). In an important study, Kremer et al. (2005) find that in their sample of Indian primary schools, 25\% of the teachers were absent during unannounced visits. According to Ramachandran et al. (2005), the state of Rajasthan alone lacked 50,000 primary school teachers. Rural areas can lack amenities that urban-educated teachers are used to. Multi-grade teaching, with one classroom and one teacher shared by all pupils, is also common.

In response to teacher absences and shortages, like many developing countries, Indian states have turned to recruiting untrained, temporary contract teachers, who are generally local to rural areas at low salaries. Despite generally being labelled as 'temporary', such "para-teachers" have become a common and persistent feature in primary schools in many Indian states. Para-teachers may be recruited to fill a vacant position, or enable a school to be established in an under-served area (under the Education Guarantee Scheme ${ }^{1}$ ). The hiring practices and pay of para-teachers vary by state and some states rely more heavily on parateachers than others. ${ }^{2}$

Concerns have been raised regarding the quality of para-teachers as well as the acceptability of their low pay (PROBE 1999, Pandey and Raj Rani 2003, Govinda and

\footnotetext{
1 http://education.nic.in/edu_guarantee.asp

2 The statistics from the District Information System for Education (DISE) for government-run primary schools for 2008 show that the highest share of para-teachers (54\%) is in Jharkand, followed by Uttar Pradesh (40\%). To name a few other states, the share in Andhra Pradesh is 11\%, 9\% in Uttarakhand, 3\% in Kerala and negligible in Karnataka and Tamil Nadu. These figures have been calculated by authors from the school-level DISE database (see Appendix 1). It must be noted that the definition of a para-teacher can vary by state depending on their recruitment policies.
} 
Josephine 2004). Regular teachers fear that the arrangement undermines the trained teacher profession. But, there is also a growing demand among para-teachers for access to training and recognition as regular teachers. Several states have experienced legal cases on this front (see e.g. Kingdon and Sipahimalani-Rao, 2010). Some states, such as Uttarakhand and Punjab, have started to accept para-teachers to training programmes to enable them to continue as teachers.

Rigorous evaluations on the effectiveness of para-teachers in India, or elsewhere, are still scarce. The limited evidence available suggests that despite lower pay, or lack of qualifications, para-teachers perform no worse than regular teachers in India and may outperform them (see Atherton and Kingdon, 2010, Goyal and Pandey, 2009, Muralidharan and Sundararaman, 2010). Studies on contract teachers in other developing countries produce somewhat more mixed results (see e.g. Bourdon, Frölich and Michaelowa, 2010, de Laat and Vegas, 2005 and Duflo et al., 2009).

A standard explanation offered for any potential difference in performance relates to the nature of the contract; namely that with a renewable contract, para-teachers are under stricter pressure to perform than those with a permanent contract. However, this may not be the only explanation. Atherton and Kingdon (2010) suggest that the low salaries paid to contract teachers as opposed to regular teachers attract individuals who are more intrinsically motivated towards teaching children in government schools and less socially distanced from the children. So far the studies on the differences between contract teachers and regular teachers have not provided clear explanations on why performance may differ.

This study sheds more light on the potential differences between para-teachers and permanent teachers, and their work motivation, by providing measurements of two key dimensions, which typically remain unobservable to researchers; job preferences and skills of teachers. As far as we know, this is the first study that jointly provides evidence on these variables in the context of public sector teachers in developing countries. The main focus is the potential trade-off between skills and preferences to work in rural, or remote, locations, that may accompany the recruitment of local para-teachers.

This study relies on a Discrete Choice Experiment (DCE) to measure the preferences of teachers. In DCEs, the indirect utility function of respondents is estimated from repeated choices of designed bundles of goods, or services, that are presented to them. This is to our 
knowledge the first study to analyse job preferences of teachers with a DCE, although the methodology has been used to study preferences of health workers. The DCE in this study focuses on the nature of the employment contract and pays particular attention to preferences over geographical location.

The study utilises the DCE to analyse the preferences of differently selected public sector workers at the training stage. The teacher students were presented with pairs of contracts from which they were asked to select the contracts they prefer. A Logit model is then used to examine how the preferences of former para-teachers differ from those of the competitively selected students and how personal characteristics affect preferences.

The teacher selection process in Uttarakhand, India, provides a unique opportunity to survey former para-teachers and competitively selected teacher students on the same training programme. The sample consists of approximately 700 respondents. All respondents were also asked to complete a simple skills test consisting of knowledge of countries, English vocabulary, and arithmetic. There is little systematic evidence on teachers' skills in India so far (with the exception of Banerji and Kingdon, 2010).

The DCE reveals significant differences in the job preferences of the two groups of teachers. In particular, para-teachers are less averse to working in remote locations than the "standard", competitively selected students, and para-teachers do not value district capitals as locations of employment. Para-teachers are also indifferent on whether contracts involve rotation as long as they are permanent, whereas the standard students strictly prefer permanent contracts without rotation. Interestingly, para-teachers also prefer larger class size. Some of the difference in preferences can be explained by life-cycle factors such as teaching experience and having children. In that regard, it is possible that the preferences of standard students will converge somewhat towards those of para-teachers, as the standard students set up families and gain more experience.

The study also finds significant differences in general skills between the two groups. Standard students obtain higher scores in all sub-tests, in particular in arithmetic. The overall conclusion is that individuals who choose to work in rural areas as para-teachers may be more content with the types of jobs available on average in the Indian public sector primary schools than those who enter through competitive examinations. However, a trade-off exists between 
the job preferences and general skills.

The article is organised as follows. Section 2 reviews the key literature and Section 3 describes the background to primary education and teacher training in India and Uttarakhand. Section 4 discusses the data and reports on the descriptive statistics and general perceptions of both types of students. Section 5 presents the details of the Discrete Choice Experiment used in the study. Finally, Sections 6 and 7 report the results and discuss robustness checks, and Section 8 concludes.

\section{Background literature}

Recent evaluation studies on teacher contracts in developing countries have focused on incentive mechanisms to motivate teachers and monitoring mechanisms to reduce absences (see e.g. Duflo et al. 2010, Glewwe et al. 2010, Kingdon and Teal, 2007, Muralidharan and Sundararaman, 2011, Banerjee et al. 2010). Another recent strand of literature focuses on hiring practices, in particular on the effects of the recruitment of local contract teachers. The latter is more relevant for our study and key results are presented below. This is followed by a brief discussion on studies using Discrete Choice Experiments to analyse job preferences.

Regarding absence rates of teachers, a study by Kremer et al. (2005) found no statistically significant difference in the absence rates of regular teachers and contract teachers. On the other hand, Kingdon and Sipahimalani-Rao (2010) show that the absence rates of para-teachers were half of those of permanent teachers in the state of Uttar Pradesh, but that there was no difference in Bihar. Muralidharan and Sundararaman (2010) report that in a sample of teachers in Andhra Pradesh, contract teachers were less likely to be absent than regular teachers.

To date, there are only a few studies that rigorously assess the effect of teacher contracts on actual pupil outcomes in India. Atherton and Kingdon (2010) use child-specific data for 4000 government school pupils in Bihar and Uttar Pradesh. With school fixed effects models, they find that students taught by para-teachers perform better, controlling for child and teacher-characteristics. Their results also indicate that some of the difference in performance may arise from contract teachers having a more beneficial impact on socially disadvantaged students.

With a cross-sectional survey of public primary schools in the state of Andhra 
Pradesh, Muralidharan and Sundararaman (2010) find that a randomly added contract teacher improves pupil test scores. In a non-experimental regression part of their analysis, the authors find that contract teachers are no less effective than regular teachers. A study by Goyal and Pandey (2009) uses teacher-specific cross-sectional data for 200 government primary schools in Madhya Pradesh and Uttar Pradesh. They find that, within schools, para-teachers exert higher effort than permanent teachers, but that effort diminishes over time, suggesting a weakening of incentives. Higher effort in general is associated with better test scores. The limited evidence available therefore suggests that despite lower pay, or lack of qualifications, para-teachers may outperform regular teachers in India.

A few studies on Sub-Saharan African countries present somewhat more mixed findings. Bourdon, Frölich and Michaelowa (2010) find that contract teachers reduce learning inequalities among students. A study using student-level data for Togo by de Laat and Vegas (2005) on the other hand finds that regular teachers outperform contract teachers. An experimental study by Duflo et al. (2009) for Kenyan schools shows that students taught by an additional, randomly assigned contract teacher have higher test scores.

By studying how para-teachers and "standard" students differ in their skills and preferences over job contracts, this study suggests some explanations for differences in the effectiveness of the two types of teachers. This connects our research to a literature on the job preferences of public sector workers. For instance, some previous studies on health workers in developing countries have found that individuals from more remote areas are in general more willing to return to work in such areas (see e.g. Chomitz et al., 1998, Serneels et al., 2005 and 2010 and Wibulpolprasert and Pengpaibon, 2003). However, studies have not yet highlighted this in the context of the discussion on para-teachers.

In order to assess how much teachers prefer different contract features, some form of a contingent valuation (or 'willingness-to-pay') method is required. This study relies on a Discrete Choice Experiment (DCE). Traditional contingent valuation methods have been criticised, for instance by Diamond and Hausman (1994) as being a "deeply flawed methodology", with many potential sources of inconsistency. Since then, DCEs have gained popularity in Health Economics, Environmental Economics and Marketing for measuring preferences over various products or services. In DCEs, the indirect utility function of respondents is estimated from repeated choices of designed bundles of goods or services that 
are presented to them. A brief survey of the method, and how it has improved elicitation of preferences, is provided by Hanley, Mourato and Wright (2001). In short, Discrete Choice Experiments are better suited to address multidimensional trade-offs and are more informative as each respondent makes multiple choices. Since the valuations are indirectly inferred from choices and the individuals choose options that represent a bundle of characteristics, there may be less scope for strategic responses.

The application of DCEs to analyse human resource policy questions is recent, but expanding. ${ }^{3}$ Their use in this field has so far been limited to health workers. In a recent review, Lagarde and Blaauw (2009) identify nine existing studies that assess how DCEs have contributed to the study of health worker preferences. Since then, a few more have appeared.

For a few studies in the context of developing countries, see e.g. Chomitz et al. (1998), Penn-Kekana et al. (2005), Hanson and Jack (2010), Mangham and Hanson (2008) and Kolstad (2011). The studies have tended to focus on the role of pecuniary versus nonpecuniary (working conditions, training) characteristics of the contract and paid less attention to the nature of the contract. Location choice has been a general component in these studies, as several have focused on the problem of attracting workers to rural locations. However, the location options may not have been very specific, often a binary urban/rural choice. In our study, the DCE focuses on the nature of the contract and pays particular attention to preferences over location by including four location categories.

In order to analyse the potential trade-off between preferences and skills, all students were also asked to complete a simple skills test. There is still little systematic evidence on teachers' skills in India. One exception is the SchoolTELLS survey, which measured teaching skills and revealed significant gaps, especially in the knowledge of Mathematics among public sector primary school teachers in 2007-08 in Bihar and Uttar Pradesh (see Banerji and Kingdon, 2010). Our test measured general/subject knowledge and not teaching skills as such. It is recognised that the two do not necessarily coincide. However, general knowledge and subject skills can still matter. For example, recent evidence by Metzler and Woessman (2010) from Peruvian primary schools shows that one standard deviation increase in teacher test scores in subject knowledge raises student test scores by 10 percent of a standard deviation.

\footnotetext{
${ }^{3}$ A recent surge of articles using DCEs for Human Resources questions in Health Economics is reviewed by Guttman, Castle and Fiebig (2009). DCEs have gained interest in this context given the absence of data sets on actual choices that public sector workers have made regarding their jobs in developing countries.
} 


\section{Primary education and teacher recruitment in India and Uttarakhand}

The Annual Status of Education Report ${ }^{4}$ is currently possibly the most reliable source of nation-wide performance data on primary school students in India. According to the 2009 report, on average 64 per cent of school children in rural India within classes 3-5 have elementary reading skills, but there is great state level variation. The figure in the state of Uttar Pradesh is $48 \%$, whilst that in Himachal Pradesh is $82 \%$ and in Madhya Pradesh $88 \%$. The state of Uttarakhand has been a somewhat above average performer, with $74 \%$ of pupils in classes 3-5 with elementary reading skills in the 2009 ASER survey. There is however considerable within state variation in Uttarakhand as shown in Table 1 below. The districts in bold are covered by our survey.

Table 1 Percentage of primary school students with elementary skills in Uttarakhand

\begin{tabular}{lccc}
\hline District & \multicolumn{3}{c}{ Grades 3-5 } \\
& Reading & Maths & English \\
\hline Pithoragarh & 90.3 & 84.4 & 23.8 \\
Nainital & $\mathbf{8 6 . 8}$ & $\mathbf{7 6 . 3}$ & $\mathbf{2 3 . 1}$ \\
Champawat & 84.6 & 67.4 & 36.7 \\
Almora & $\mathbf{8 2 . 6}$ & $\mathbf{7 9 . 8}$ & $\mathbf{2 0 . 9}$ \\
Chamoli & $\mathbf{7 7 . 6}$ & $\mathbf{6 8 . 2}$ & $\mathbf{1 0 . 5}$ \\
Garhwal & 77.4 & 66.8 & 19.9 \\
Rudraprayag & $\mathbf{7 3 . 1}$ & $\mathbf{5 6 . 7}$ & $\mathbf{1 4 . 5}$ \\
Tehri Garhwal & 72 & 53.2 & 28.9 \\
Uttarkashi & 69.2 & 46.9 & 19.2 \\
Bageshwar & 66.1 & 57.8 & 10.5 \\
Dehradun & $\mathbf{6 4 . 1}$ & $\mathbf{5 0 . 8}$ & $\mathbf{2 8 . 6}$ \\
Haridwar & $\mathbf{6 4}$ & $\mathbf{5 3 . 4}$ & $\mathbf{3 3 . 8}$ \\
Udham Singh Nagar & $\mathbf{5 8 . 3}$ & $\mathbf{4 1 . 6}$ & $\mathbf{2 0 . 6}$ \\
\hline
\end{tabular}

Source: Annual Status of Education Report (2009). Ordered by "reading" score. The data are collected at the household level, so pupils in both public and private schools are included. Districts in bold are covered by our survey.

In Uttarakhand, training for public sector primary school teachers is provided exclusively by public sector training institutes, the District Institutes for Educational Research and Training (DIETs). The State Council for Educational Research and Training (SCERT) oversees the DIETs. The DIETs organise both full-scale teacher training programmes as well

\footnotetext{
${ }^{4} \mathrm{http}: / /$ www.asercentre.org/
} 
as shorter training courses for existing teachers and inspectors. A new two-year programme, the Basic Teaching Certificate (BTC) was initiated in April 2010. ${ }^{5}$ The BTC training is required to be able to work as a regular teacher in a public sector primary school. There are a total of 13 DIETs in Uttarakhand, of which 3 are so called "mini-DIETs", given that they are located in districts with a smaller number of schools.

Uttarakhand formed part of the state of Uttar Pradesh until 2000. In the 2001 Census, the state is reported to have 8.5 million inhabitants, and $90 \%$ of the population depends on agriculture. ${ }^{6}$ The state is relatively small geographically in comparison to many other Indian states, but its territory consists mainly of mountains. Travel times can be long even between short distances, and therefore remote locations pose a clear challenge for teacher recruitment.

Para-teachers have been used to staff schools in Uttarakhand, in particular in rural and more remote locations. In this case, these teachers have generally had the characteristics of standard "contract teachers": they do not have formal teaching qualifications and are employed on a contract basis with significantly lower salaries than those of regular teachers. ${ }^{7}$ However, the government has recently decided to end the recruitment of para-teachers and offer BTC training for the existing para-teachers to enable them to become regular teachers. The current starting salary of a regular teacher in Uttarakhand has recently been raised to approximately Rs. 17,000 per month. A "cost of living" allowance as well as "a hill area" allowance are provided in some circumstances, and a "housing allowance" if appropriate government accommodation is unavailable. ${ }^{8}$ The starting salary is considerably higher than in some other states, although there have been recent increases elsewhere as well following the recommendations of the Sixth Pay Commission (see e.g. Kingdon, 2010). However, recent discussions suggest that the state of Punjab for instance still pays only approximately Rs. 5000-6000 for its regular public sector teachers. ${ }^{9}$ In Uttarakhand, para-teachers have been paid up to Rs. 6000 per month in recent years.

\footnotetext{
${ }^{5}$ There has been a ten-year break in the provision of regular training programmes. (see Godiyal and Nautiyal, 2008).

${ }^{6} \mathrm{http}: / /$ www.india.gv.in/knowindia/st_uttaranchal.php

7 The combination of a lack of formal qualifications, and the temporary nature of the contract may not be characteristic of all "para-teachers" in India. According to Ramachandran (2009) "In some states such as Kerala, for example, a few 'contract' teachers have been appointed, supposedly as a purely temporary and stopgap measure. At the other end of the spectrum, Madhya Pradesh had [...] decided to discontinue the appointment of regular teachers [...]. In between these extremes, we find Maharashtra, where all new primary level teachers are appointed on a three-year contract and with a low honorarium, even though their qualifications are the same as 'regular' primary teachers; after three years, they are eligible for appointment as 'regular' teachers."

${ }^{8}$ Source: Communication with officials at Uttarakhand Sarva Shiksha Abhiyan office.

${ }^{9}$ Source: Communication with officials in the SCERT in Punjab.
} 
There are currently approximately 200 students in each DIET $^{10}$ on the new training programme, of which roughly half are former para-teachers. Almost all students in the district specific DIETs come from the same district. They will also be recruited as teachers in the same district.

The former para-teachers were selected to the programme at the village level. The number of years of teaching experience appears to have been one decisive factor for their selection, but there are other less well-defined criteria as well. The "standard" students were selected on the basis of a composite entry score. This is based on the performance in an entrance exam as well as other merits (such as existing degrees, education) or quota-related characteristics, but the female-male ratio should be 50:50 (see Godiyal and Nautiyal, 2008). We were reported that upon completion of the programme, the former para-teachers are supposed to be sent back to their original location, and the others will be sent to a rural location for 10 years. The choice of initial location can be based on merit and success in the BTC programme, but this is a murky area. ${ }^{11}$

Regular teachers can generally request for transfers of location, or are at times transferred without request, and this is another controversial issue in India. In a summary of her research, Béteille (2009) explains how half of the teachers she surveyed in the states of Rajasthan, Madhya Pradesh and Karnataka agreed that transfers require connections and 30 percent believed that they would have to pay to obtain the post they wanted. Ramachandran et al. (2005) report that in their survey, the share of teachers explicitly wanting a transfer was not large. However, mass transfers occurred now and then. In 2005, the government in Rajasthan transferred 20,000 teachers in one occasion, which generated general unrest. To quote the authors:

"Discussions with trade union leaders revealed that transfers and posting were big business in Rajasthan. Intensive lobbying followed bulk transfers and it was rumoured that political middlemen demanded Rs. 5,000 to Rs. 25,000 to cancel the transfer or ensure a good posting."

\footnotetext{
${ }^{10}$ The numbers are smaller (roughly 100) in the "mini" DIETs.

11 Source: Communication with various education officials in Uttarakhand.
} 


\section{Data and descriptive statistics}

The survey was carried out in DIETs in seven out of 13 districts of Uttarakhand. The state of Uttarakhand was chosen for its manageable size, but also the introduction of a new teachertraining programme, including both former para-teachers and competitively selected students. The survey was conducted in May 2010, right after the students (both standard students and former para-teachers) had entered the BTC programme.

Since the students had only recently entered the training programme, it can be assumed that the programme itself had not yet significantly shaped their skills or preferences. Thus, it provides a picture of para-teachers "as they are" and standard students in the first stage of their career. One distinguishing factor between the two groups of students is that para-teachers have more teaching experience. However, compared to the existing studies on para versus permanent teachers already working in schools, there is rather little difference in the mean age between the two groups. The study captures all teachers at an entry point to their careers as regular public sector teachers. Although the selection process of both para and normal teachers may vary somewhat across states, it is reasonable to expect that the results are relevant to other Indian states.

The main criteria for the choice of districts were diversity in geography and diversity in pupil outcomes (as seen above in Table 1). It was considered appropriate to sample two geographically "flat" districts (Haridwar and Udham Singh Nagar) where conditions resemble those of other Northern Indian States. In addition, the district including the state capital was included (Dehradun). Out of the remaining four sampled districts, two can be considered remote mountain districts (Chamoli and Rudraprayag) and two less remote, mountainous districts (Almora and Nainital). More details of the data collection process are presented in Appendix 1.

The questionnaire given to the participants consisted of three parts. Part I focused on the general background of the students and their perceptions on the recruitment and work of teachers. This was followed by the discrete choice experiment (part II) and a timed, voluntary general skills test (part III). The questions in the survey and job characteristics incorporated in the DCE were decided after discussions with a range of Indian education officials and academics, including officials in the state of Uttarakhand. The design was also influenced by findings in existing literature referred to above. A vast majority of the students had at least 
some teaching experience, and thus the presented choices should not be alien to them. The questionnaire as well as verbal instructions were given in both English and Hindi (the main language in the state). This section reports on the responses to part I as well as the results of the skills tests. The replies to the DCE are described in Section 5.

\subsection{Profile of students}

A total of 707 students participated in the survey of whom $39 \%$ said they entered the BTC programme as para-teachers. Table 2 summarises the data on the background and characteristics of the students separately for the former para-teachers and the standard students. There are some significant differences.

Whereas $61 \%$ of the standard students come from rural areas, $97 \%$ of the former parateachers say they come from rural areas. Para-teachers are also much more likely to be married and have on average more children. The average age of a para-teacher is 33 years, and that of a standard student is 29 years. The parents of para-teachers are less educated and come from homes with fewer possessions on average, with the exception of land. Former para-teachers have on average 8.2 years of teaching experience, while standard students have an average of 1.7 years of teaching experience, in the latter case typically from the private sector. Approximately half of the standard students have worked as a teacher in the private sector, whereas the corresponding figure is $15 \%$ for the para-teachers. The wage that parateachers had earned as private sector teachers was less than half of the wage earner by the standard students. This is likely to be explained by location, but potentially also differences in skills. Almost everyone who had worked as a para-teacher reported a current standard salary of 6000 Rs. per month. Some noted that the standard salary had initially been lower, around Rs. 2500 per month. There are no striking differences between the religion or caste status of the former para-teachers and the standard students (not reported in the table). Almost all of the students are hindus and in both student categories, about $40 \%$ belong to a scheduled caste or tribe, or other backward caste. 
Table 2 Summary statistics

\begin{tabular}{|c|c|c|c|c|c|c|c|}
\hline \multirow[b]{2}{*}{ Variable } & \multicolumn{3}{|c|}{ Standard students } & \multicolumn{3}{|c|}{ Para-teachers } & \multirow[b]{2}{*}{ Difference } \\
\hline & Obs & Mean & S.D. & Obs & Mean & S.D. & \\
\hline Female* & 425 & .52 & .50 & 277 & .50 & .50 & 0.02 \\
\hline Birth year & 413 & 1981 & 3.0 & 251 & 1978 & 3.6 & $3.60 * *$ \\
\hline Married* & 424 & .47 & .50 & 276 & .89 & .31 & $-0.42 * *$ \\
\hline \# Children & 425 & .52 & .80 & 277 & 1.74 & 1.07 & $-1.22 * *$ \\
\hline Father's Education ${ }^{1}$ & 405 & 3.70 & 1.22 & 249 & 2.72 & 1.25 & $0.98 * *$ \\
\hline Mother's Education' & 411 & 2.45 & 1.30 & 252 & 1.64 & .87 & $0.81 * *$ \\
\hline \multicolumn{8}{|l|}{ Parents own: } \\
\hline House* & 426 & .91 & .29 & 278 & .72 & .45 & $0.19 * *$ \\
\hline Car* & 426 & .10 & .30 & 278 & .04 & .20 & $0.06 * *$ \\
\hline Land* & 426 & .55 & .50 & 278 & .68 & .47 & $-0.13 * *$ \\
\hline Computer* & 426 & .28 & .45 & 278 & .05 & .23 & $0.23 * *$ \\
\hline Teaching Experience ${ }^{2}$ & 402 & 1.73 & 2.25 & 257 & 8.18 & 2.32 & $-6.45 * *$ \\
\hline Private school experience* & 415 & .55 & .50 & 267 & .16 & .37 & $0.39 * *$ \\
\hline Monthly private pay (Rs.) & 228 & 4165 & 3423 & 41 & 2011 & 2657 & $2154 * *$ \\
\hline MSc Degree* & 424 & .80 & .40 & 276 & .55 & .50 & $0.25 * *$ \\
\hline Rural* & 421 & .61 & .49 & 271 & .97 & .16 & $-0.36 * *$ \\
\hline \multicolumn{8}{|l|}{ Skills test: } \\
\hline Countries (\#) & 425 & 16.89 & 4.43 & 278 & 14.72 & 4.01 & $2.17 * *$ \\
\hline Arithmetic (\#) & 422 & 30.01 & 7.96 & 273 & 24.13 & 8.44 & $5.88 * *$ \\
\hline English (\#) & 424 & 10.87 & 3.67 & 277 & 8.54 & 3.60 & $2.33 * *$ \\
\hline Skills $-1^{\text {st }} \mathrm{PC} \sim$ & 421 & .29 & .92 & 272 & -.45 & .95 & $0.74 * *$ \\
\hline
\end{tabular}

Notes: * dummy variable, ${ }^{1}=$ less than primary school (1), primary school (2), secondary school (3), higher secondary school (4), university degree (5). ${ }^{2}=$ years of experience in private or public sector school. A total of 707 individuals, selection status is unknown for 3 students. $\sim$ First normalised principal component of the three skill measures. 1 USD $~ 45$ Rupees. ** significant at the $1 \%$ level.

The competition for places on the BTC programme is considered fierce for the standard students. The surveyed students all already hold at least a bachelor level degree. In terms of education, $80 \%$ of the standard students hold a Masters degree, while $57 \%$ of the para-teachers hold a Masters degree. India-wide statistics show that on average para-teachers have higher educational qualifications than permanent teachers, but this is likely to be due to the fact that para-teachers are on average younger than permanent teachers currently teaching in schools. Despite the relatively high stated levels of education, $34 \%$ of those in the sample say they would be studying for another degree had they not been accepted to the BTC. Attractive work is scarce and the teaching profession desirable. 


\subsection{Skills}

The surveyed students were asked to participate in a voluntary timed test of simple generic skills, which focused on knowledge of countries, English, and Arithmetic. A detailed description of the tests and their first principal component can be found in Appendix 2. The test was not designed to test whether teachers' skills matched the expected level of those of relevant students, but moreover to demonstrate a general level of knowledge in the three areas. The average scores obtained by the two groups are shown in Table 2 and Figure 1 below shows the distributions of the test scores across the two groups. This is a general skills test not designed to specifically test for teaching skills. As mentioned above, teachers' subject knowledge can affect learning, but teaching skills evidently also depend on various other factors, overall motivation potentially being a very important one.

\section{Figure 1 Differences in skills between para-teachers and standard students: Kernel}

\section{densities}
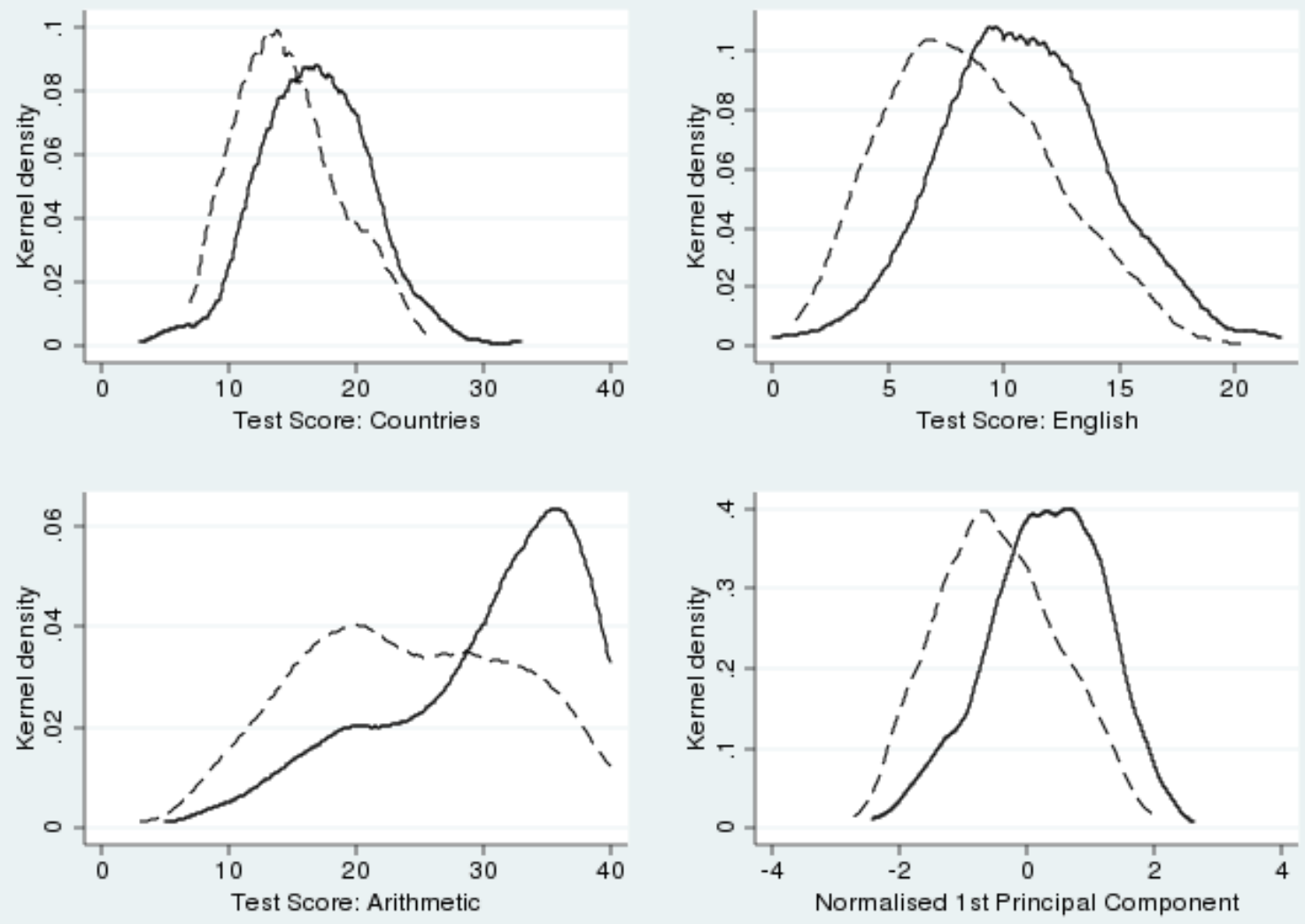

Notes: Solid line: standard students, dashed line: para-teachers. 
Overall, there are significant differences between the groups in all tests. The differences are particularly large in the arithmetic test. The mode for standard students in the arithmetic test is 35 (out of 40 problems) and that for para-teachers is 20 (out of 40 problems). It is difficult to determine what represents a "good" score in the arithmetic test for primary school teachers, but based on the responses it was apparent that students who scored below 20 were struggling with arithmetic computations - either by making many mistakes or by running out of time. Some students did well with addition and subtraction, but were discouraged by multiplication or division. The full test can be found in Appendix 2.

\section{Discrete choice experiment: econometric model}

In the experiment, all students were presented with pairs of contracts from which they had to select the one they prefer. These represented hypothetical contracts with characteristics that were deemed to be generally important and relevant for a teacher's job. To elicit a sufficient amount of information regarding their preferences over the characteristics (attributes) of the contracts, the selection was repeated multiple times with different levels of the contract attributes. In our case, the number of contract pairs was 12 (see Appendix 3 for a justification). The contract attributes and their levels are presented in Table 3 below. An example contract pair is presented in Appendix 3. This section of the questionnaire was not timed; the students were given the amount of time they required to complete the section. All students received the same contract pairs to choose from.

The students were explained that this was an independent study and that all responses would remain confidential and would not be revealed to education officials, or members of staff at the school. The aim was to minimise the tendency to provide "correct" answers as opposed to true preferences. As mentioned earlier, the multi-dimensionality of the DCE framework also mitigates such tendencies, unless respondents in reality only make decisions based on a specific job characteristic. A robustness check that excludes such individuals will be discussed in connection with the results.

There are limitations to how many attributes can be chosen to be able to estimate the DCE. The results described in the next section show that the chosen attributes had a statistically significant contribution to individuals' choices. The incorporation of pay was considered necessary, as it was likely to be of fundamental importance and necessary to 
calculate monetary valuation of other attributes. The attributes and their levels were chosen to be relevant and approximately realistic for the state of Uttarakhand and India to a large extent.

As mentioned, it was considered appropriate to include more than two location categories. For instance, from the perspective of recruitment policy, it would be useful to know to what extent students prefer to work in their home village or town. An attribute on the contract type was also considered important, given the concerns with permanent contracts and increased tendency to recruit teachers on a contract basis in India. The existing studies on job preferences by public sector workers referred to above have tended to ignore this dimension.

The attribute levels for the contract types incorporate both geographic rotation ${ }^{12}$ and permanence of the contract. Given the political nature of teacher recruitment and transfers, we considered it appropriate to include an attribute on transfer policies. Formulating a DCE question on the topic was challenging, but we wanted to understand how teachers value meritbased transfers as opposed to ones based on 'connections and influence'. The final attribute, the teacher-pupil ratio, is included as a general indicator of the demand level of the job.

A discrete choice regression model is then used to analyse the relative importance of different attributes in choices and especially, whether location options significantly affect choices. As explained below, the analysis allows one to assess on what terms teachers would be willing to trade one job characteristic for another.

\footnotetext{
${ }^{12}$ Rotation and compulsory service in rural areas after graduation have been common practices used for instance in the health sector in developing countries (see e.g. WHO, 2006).
} 
Table 3 DCE: Contract attributes, and their levels

\begin{tabular}{l|l|l|l|l|}
\hline \multicolumn{1}{c|}{ Pay } & \multicolumn{1}{c|}{ Location } & \multicolumn{1}{c|}{ Contract } & \multicolumn{1}{c|}{ Transfers } & Staff and pupils \\
\hline $\begin{array}{l}\text { Rs. 13000 per } \\
\text { month }\end{array}$ & Remote village & $\begin{array}{l}\text { Fixed term } \\
\text { contract, renewable } \\
\text { every 7 years. }\end{array}$ & $\begin{array}{l}\text { Depend on } \\
\text { connections and } \\
\text { influence }\end{array}$ & $\begin{array}{l}2 \text { teachers, 75 } \\
\text { pupils }\end{array}$ \\
\hline $\begin{array}{l}\text { Rs. 17000 per } \\
\text { month }\end{array}$ & Village / Small town & $\begin{array}{l}\text { Permanent, must } \\
\text { transfer every 7 } \\
\text { years. }\end{array}$ & Depend on merit & $\begin{array}{l}\text { 2 teachers, 14 } \\
\text { pupils }\end{array}$ \\
\hline $\begin{array}{l}\text { Rs. 21000 per } \\
\text { month }\end{array}$ & $\begin{array}{l}\text { Your home village / } \\
\text { town }\end{array}$ & $\begin{array}{l}\text { Permanent, } \\
\text { possibility to } \\
\text { transfer after 7 } \\
\text { years. }\end{array}$ & & \\
\hline & District capital area & & & \\
\hline
\end{tabular}

Notes: 1 USD $\sim 45$ Rupees. The current teacher starting salary in Uttarakhand is 17-18.000 Rs per month (USD $378-400)$

\subsection{The model}

Following the much used random utility framework (McFadden, 1974), we assume that utility from a job contract can be characterised by a function

(1) $U_{c i}=\alpha+\sum_{k=1}^{K} \beta_{k} X_{c k i}+\sum_{m=1}^{M} \gamma_{m} Z_{m i}+\sum_{k=1}^{K} \sum_{m=1}^{M} \delta_{k m} X_{c k i} Z_{m i}+u_{c i}$

where contract $c=\{A, B\}$ and $i=1 \ldots \mathrm{N}$ refers to individuals. $X$ is a vector of $K$ attribute levels, and $Z$ is a vector of $M$ personal characteristics. The term $u_{c i}$ is random and represents unobservable influences on individual choice. Now, the utility gain from contract $B$ over contract $A$ for individual $i, U_{i}(B)$, is:

(2) $U_{i}(B)=U_{B i}-U_{A i}=\sum_{k=1}^{K} \beta_{k}\left(X_{B k i}-X_{A k i}\right)+\sum_{k=1}^{K} \sum_{m=1}^{M} \delta_{k m}\left(X_{B k i}-X_{A k i}\right) Z_{m i}+\left(u_{B i}-u_{A i}\right)$

The random component $u_{c i}$ may be hypothesised to consist of three additive components: an individual specific component $v_{i}$, a contract specific component $e_{c}$ and a true iid random term 
$\varepsilon_{c i}$. Of these, the individual specific term cancels out. The contract specific component can be assumed to be zero, unless the respondents have a consistent tendency to be more or less likely to respond to contract $A$ instead of $B$, for instance due to their placement (this will be tested below as a robustness check). Suppose the individual chooses contract $B$ if $U_{i}(B)>0$. This takes place with the probability

$$
\begin{aligned}
& P_{i}(B)=P\left[U_{i}(B)>0\right]=P\left[\sum_{k=1}^{K} \beta_{k}\left(X_{B k i}-X_{A k i}\right)+\sum_{k=1}^{K} \sum_{m=1}^{M} \delta_{k m}\left(X_{B k i}-X_{A k i}\right) Z_{m i}+\left(u_{B i}-u_{A i}\right)>0\right] \\
& \text { 3) } \quad=P\left[\left(u_{A i}-u_{B i}\right)<\sum_{k=1}^{K} \beta_{k}\left(X_{B k i}-X_{A k i}\right)+\sum_{k=1}^{K} \sum_{m=1}^{M} \delta_{k m}\left(X_{B k i}-X_{A k i}\right) Z_{m i}\right] .
\end{aligned}
$$

Assuming a distribution for $\left(u_{A i}-u_{B i}\right)$, for instance a logistic distribution, the probability in (3) can be expressed in terms of a distribution function of a logistic distribution and modelled accordingly with Logit:

(4) $P_{i}(B)=F\left[\sum_{k=1}^{K} \beta_{k}\left(X_{B k i}-X_{A k i}\right)+\sum_{k=1}^{K} \sum_{m=1}^{M} \delta_{k m}\left(X_{B k i}-X_{A k i}\right) Z_{m i}\right]$,

where $F(\mathrm{x})=\exp (\mathrm{x}) /(1+\exp (\mathrm{x}))$. This paper estimates Equation 4 with Logit in all cases, but the results are virtually the same if one would use Probit instead. The levels of the contract attributes are treated as separate dummy variables in the regression analysis, except for pay which enters as a continuous variable with three values. The estimated models are based on differenced contracts attributes as specified in Equations (2)-(3). Since the explanatory variables represent the differences between the attribute levels of two contracts, it is unnecessary to include individual effects (such as random effects). Appendix 3 describes the design of the DCE in more detail.

One downside of a discrete choice experiment is that the interview setting does not constitute a real, but a stated choice. Some studies have been carried out to assess the reliability of stated preference in predicting actual behaviour, and they tend to show good correspondence (e.g. Adamowicz et al., 1994). In the context of health worker preferences, Chomitz et al. (1998) find a "strong qualitative consistency" between stated and revealed preference. Further, the questions can be constructed so as to extract the maximum amount of 
information from the respondents, and the consistency of the responses can be evaluated in some cases (see e.g. Mangham et al., 2008, Street et al., 2005).

\section{Results}

The results of the discrete choice estimations are shown in Table 4. The coefficients in the Table refer to the estimated $\beta: \mathrm{s}$ and $\delta: \mathrm{s}$ of Model (1)-(4), and they measure whether the attribute levels make respondents more likely to choose contract B. Reference groups (for dummy variables) are excluded from the models. For location, the reference group is "Remote village". For the contracts, the reference group is "Fixed term contract, renewable every 7 years". For transfers, the base category is "Transfers based on connections and influence", and for pupils and staff, the excluded category is " 2 teachers, 75 pupils" ("Large class size"). Thus, the estimated parameters refer to preferences compared to these categories - a significant positive estimated coefficient measures how much the option is preferred in relation to the excluded category. The differences between the preferences of the standard students and the para-teachers are measured by the eight interaction terms in Model 1 of Table 4.

\subsection{Preferences of standard students versus para-teachers}

The basic preference parameters for both standard students and para-teachers are presented in the first column of Table 4. The model utilises all available data. So far, the estimation ignores the observable characteristics of students with the exception of para-teacher status. In the framework of equation (3), a para-teacher dummy is the only variable included in $Z$.

With the exception of "small class size", the coefficients for all job attribute levels are statistically significant, which implies that they affect choices and are relevant. As the main purpose of this study is to assess the differences between the two types of students, focus is on the difference between the coefficients for the two groups of students, or the interaction terms. 
Table 4 Logit estimates of the DCE model

\begin{tabular}{|c|c|c|c|c|}
\hline & [1] & [2] & [3] & [4] \\
\hline Contract attributes & Basic & $\begin{array}{c}\text { Basic } \\
\text { Sample [2]-[4] }\end{array}$ & $\begin{array}{c}\text { Life-cycle } \\
\text { controls }\end{array}$ & All controls \\
\hline Pay (1000 Rs) & $.129[.008]^{* *}$ & $.128[.008]^{* *}$ & $.139[.013]^{* *}$ & $.131[.022]^{* *}$ \\
\hline Location: Village / Small Town & $.573[.065]^{* *}$ & $.593[.067]^{* *}$ & $.680[.113]^{* *}$ & $.703[.185]^{* *}$ \\
\hline Location: Home village / town & $1.021[.068]^{* *}$ & $.995[.070]^{* *}$ & $1.143[.119]^{* *}$ & $.918[.192]^{* *}$ \\
\hline Location: District capital area & $.636[.067]^{* *}$ & $.646[.069]^{* *}$ & $.731[.117]^{* *}$ & $.748[.190]^{* *}$ \\
\hline Contract: Permanent, with rotation & $.545[.047]^{* *}$ & $.570[.048]^{* *}$ & $.532[.081]^{* *}$ & $.719[.133]^{* *}$ \\
\hline Contract: Permanent & $.735[.070]^{* *}$ & $.739[.072]^{* *}$ & $.730[.121]^{* *}$ & $.741[.198]^{* *}$ \\
\hline Transfers: Based on merit & $1.052[.052]^{* *}$ & $1.032[.054]^{* *}$ & $1.023[.091]^{* *}$ & $.801[.148]^{* *}$ \\
\hline Small class size & $-.064[.041]$ & $-.071[.042]+$ & $-.009[.071]$ & $-.156[.116]$ \\
\hline \multicolumn{5}{|l|}{ Interaction terms } \\
\hline Para $\times$ Pay $(1000$ Rs $)$ & $-.029[.012]^{*}$ & $-.021[.013]+$ & $-.013[.016]$ & $-.007[.018]$ \\
\hline Para $\times$ Village / Small Town & $-.129[.104]$ & $-.201[.107]+$ & $-.116[.136]$ & $.027[.152]$ \\
\hline Para $\times$ Home village / town & $-.455[.105]^{* *}$ & $-.432[.108]^{* *}$ & $-.333[.138]^{*}$ & $-.055[.154]$ \\
\hline Para $\times$ District capital area & $-.574[.105]^{* *}$ & $-.630[.109]^{* *}$ & $-.551[.138]^{* *}$ & $-.236[.155]$ \\
\hline Para $\times$ Permanent, with rotation & $-.058[.074]$ & $-.086[.076]$ & $-.053[.097]$ & $.006[.108]$ \\
\hline Para $\times$ Permanent & $-.151[.108]$ & $-.123[.112]$ & $-.093[.144]$ & $.024[.161]$ \\
\hline Para $\times$ Based on merit & $-.405[.081]^{* *}$ & $-.374[.084]^{* *}$ & $-.342[.107]^{* *}$ & $-.237[.119]^{*}$ \\
\hline Para $\times$ Small class size & $-.086[.064]$ & $-.107[.066]$ & $-.068[.084]$ & $-.119[.095]$ \\
\hline Kids $\times$ Permanent, with rotation & & & $-.280[.085]^{* *}$ & $-.216[.090]^{*}$ \\
\hline Kids $\times$ Based on merit & & & $-.206[.095]^{*}$ & $-.168[.100]+$ \\
\hline Exper. $\times$ Home village $/$ town & & & $-.260[.142]+$ & $-.382[.146]^{* *}$ \\
\hline Exper. $\times$ Permanent, with rotation & & & $.238[.098]^{*}$ & $.243[.100]^{*}$ \\
\hline Female $\times$ Pay $(1000$ Rs $)$ & & & & $-.023[.014]+$ \\
\hline Female $\times$ Village $/$ Small Town & & & & $.224[.116]+$ \\
\hline Female $\times$ Home village $/$ town & & & & $.656[.120]^{* *}$ \\
\hline Female $\times$ District capital area & & & & $.316[.119]^{* *}$ \\
\hline Female $\times$ Permanent, with rotation & & & & $-.269[.083]^{* *}$ \\
\hline Female $\times$ Based on merit & & & & $.276[.092]^{* *}$ \\
\hline Female $\times$ Small class size & & & & $.231[.073]^{* *}$ \\
\hline Skills $\times$ Pay $(1000$ Rs $)$ & & & & $.014[.007]+$ \\
\hline Skills $\times$ Home village $/$ town & & & & $.202[.065]^{* *}$ \\
\hline Skills $\times$ Permanent & & & & $.207[.067]^{* *}$ \\
\hline Skills $\times$ Based on merit & & & & $.146[.049]^{* *}$ \\
\hline MSc $\times$ District capital area & & & & $.250[.125]^{*}$ \\
\hline Rural $\times$ Village / Small Town & & & & $-.281[.139]^{*}$ \\
\hline Rural $\times$ District capital area & & & & $-.541[.144]^{* *}$ \\
\hline DCE responses & 8198 & 7735 & 7735 & 7735 \\
\hline Individuals & 685 & 665 & 665 & 665 \\
\hline
\end{tabular}

$* * *,+$ : significant at the $1 \%, 5 \%$ and $10 \%$ levels respectively. Kids = dummy for having children, Exper. $=$ teaching experience dummy, Skills $=$ First principal component of skills test, Rural $=$ dummy for rural home 
location. To save space, for the additional control variables, only coefficients that are statistically significant are reported for models 3 and 4 .

From the perspective of this study, possibly the most important results relate to preferences over locations. Both groups regard the "Remote village" as the least desirable option. However, the results suggest that para-teachers do not value the "District Capital" over the "Remote village" option, which is the reference group. This can be seen by testing whether the sum of the estimated coefficients .636-.574 $=.063$ is significantly different from zero, which it is not $(p=.44)$. At the same time, while para-teachers value their "Home town/village" significantly more than the "Remote village" $(1.021-.455 \neq 0, p=.00)$, the preference for "Home village/town" is much stronger for standard students $(-.455 \neq 0, p=$. 00) . This observation is somewhat more surprising considering the fact that para-teachers are often mothers, or fathers, of a settled family and have been working in their home area. On the other hand, the para-teachers may have been selected from less desirable locations to begin with, and the result could reflect the willingness of some para-teachers to move out from their current village/town. They may also simply value change having worked in their home village for several years.

Para-teachers and standard students both clearly prefer a permanent contract over a fixed term contract, but the aversion of rotation is not particularly strong. In fact, parateachers are indifferent regarding whether the contract includes rotation, as long as the contract is permanent, i.e. (.545-.058)-(.735-.151) is not significantly different from zero ( $\mathrm{p}$ $=.34)$. Standard students on the other hand value a permanent contract without rotation over a permanent contract with rotation $(.735-.545 \neq 0, p=.024)$.

Both groups clearly prefer jobs where transfers are based on merit rather than connections and influence, and this tendency is particularly strong among the standard students. With respect to class size, the standard students are indifferent in terms of whether they are placed in a school with 14 or 75 pupils per two teachers. Para-teachers on the other hand, actually prefer the larger school $(-.064-.086 \neq 0, \mathrm{p}=.003)$. Our prior assumption was that the teachers would prefer smaller schools due to a lighter workload, but it may be that the teachers truly prefer more students in order for their work to have a larger impact. An alternative explanation is that the respondents associate the larger student body with other job features such as a better school building and facilities, as these are not specified in the 
alternative contracts. The difference in the number of students between the two levels was deliberately large ${ }^{13}$, but the choices may have been different had the difference been smaller.

\subsection{Explaining the differences}

The results of the first model suggest that para-teachers and standard students differ in their preferences in some important respects. However, it is important to examine whether these differences are of a fundamental nature or simply due to observable differences that become less significant over the life cycle. For instance, we know from above that para-teachers have considerably more teaching experience, are more likely to be married and have more children than the standard students. To what extent would these differences explain the differences in preferences? Is it possible that in a few years, when normal teachers have gained more experience, and had more children, the differences in preferences disappear?

Column 3 of Table 4 shows estimates for models that include interaction terms between the job attributes and two "life-cycle" variables, dummy variables for whether the individuals have children and teaching experience. This lowers the number of available observations as not everyone reported all the details on characteristics. Interaction terms with all contract attributes were included, but the estimated coefficients are only shown when they are statistically significant at least at the $10 \%$ significance level.

A dummy variable for teaching experience in the private, or public, sector is included instead of the actual years of teaching experience, as the correlation of the latter with parateacher status is very strong. ${ }^{14}$ Control variables for age and marital status were not highly statistically significant after experience and the dummy for children were included. Column 2 shows the results of the specification in column 1 with the sample used in columns 3 and 4 . The changes in the significances of the variables are not large.

A comparison of the estimates in columns 2 and 3 shows that "life-cycle" characteristics explain the difference in preferences between para-teachers and standard students only partly. This conclusion is based on the observation that several of the coefficients on the para-teacher interaction terms still remain statistically significant after controlling for life-cycle factors. The valuation of a contract with rotation as opposed to temporary, and a contract with meritocratic transfers as opposed to ones based on

\footnotetext{
${ }^{13}$ Based on DISE 2008 data, $10 \%$ of two-teacher public sector schools in Uttarakhand have 75 students or more, and $10 \%$ have 14 students or less.

${ }^{14}$ Care was taken not to include interaction terms that would lead to significant multicollinearity.
} 
connections, fall with children. Both of these can be consistent with the fact that having children makes moving more difficult, and individuals are less interested in rotation and transfers, and thus become more indifferent between transfer options. Since para-teachers have on average more children, these factors could explain the differences in the preferences of para-teachers and standard students, although in this case their contribution does not appear to be particularly large. The other life-cycle factor examined is teaching experience. The results show that with experience, teachers are more indifferent between home and a remote location, although still prefer home. This can explain partly why para-teachers are more indifferent between home and remote location than the standard students, possibly because they have already taught in their home location for a long period. With experience, the valuation of a permanent contract with rotation also rises, although adding this control does not clearly lead to a large change in the interaction terms for para-teacher status as one moves from columns (2) to (3).

The model in column 4 of Table 4 shows the results of a model with interaction terms for a larger number of personal characteristics. In addition to the life-cycle variables, all job attribute variables are interacted with a female dummy, the first principle component for skills, a dummy variable for a Masters degree and a dummy for rural home location. In principle, other interaction terms could have been included as well, but their relevance was questionable in particular since there is a risk of significant multicollinearity with an increasing number of interaction terms. Given the number of interaction terms, again only coefficients that are statistically significant at least at the $10 \%$ significance level, are shown.

The results show that the preferences of women differ significantly from those of men. However, this is unlikely to explain the differences between the preferences of para-teachers and standard students, since the gender balance is approximately equal in both groups. Women dislike remote locations more than men. They have a significantly higher preference for home location, but also for villages/smaller towns and the district capital as opposed to the base category "Remote village". This corroborates with our discussions with district level education officials who noted that women are generally less likely to be placed in remote locations. In our sample, women also have a stronger preference for a permanent contract without rotation as opposed to a permanent contract with rotation or a temporary contract. Women value pay slightly less than men, and small class size and meritocratic transfers more. An intuitive explanation cannot be provided for all these differences, but given that women 
generally have less power in the society the preference for transfers based on merit seems understandable.

Standard students are more educated and the remaining interaction terms show that a Masters degree raises the preference for district capital. A larger share of para-teachers comes from rural areas and a rural home location lowers the preference for district capital, or small village/town, as opposed to a remote location. The scores of the standard students in the skills test are on average higher than those of para-teachers. A higher score raises the preference for higher pay, home location, the preference for a permanent contract without rotation and meritocratic transfers.

After all of the different characteristics are controlled for, most of the coefficients for the para-teacher interaction terms become statistically insignificant. The exception is the remaining significantly lower preference of para-teachers for meritocratic transfers. This may be explained by the features of the selection process for the para-teachers. Thus, the differences in the preferences of para-teachers and standard students appear to be largely explained by observable characteristic. Differences in teaching experience and family size appear to explain some of the differences. However, rural origin, skills and qualifications also play a clear role in explaining why para-teachers and standard students on average differ in their preferences over job contracts.

\subsection{Monetary valuations}

Finally, the results show that both groups clearly appreciate higher pay and that this tendency is somewhat stronger for standard students. In the model, pay has been measured in thousands of rupees. An additional benefit of estimating the 'preference for money' is that it allows us to compute the monetary equivalents of different job characteristics, based on the estimated utility impacts of the contract features.

At this point it is important to be clear about the assumptions underlying the estimates. Since the utility function is assumed to be linear, the estimates assume perfect substitutability between contract attributes. While this is a simplification, it allows for simple comparisons of contract features. For example, in the case of standard students, an additional 1000 rupees per month increases utility on average by .129 , and being located in the district capital instead of a remote village increases utility by .636 . These figures suggest that $1000 \times(.636 / .129)=4930$ rupees per month would be the amount that would make a teacher equally content with a 
remote village as with a district capital, assuming that all other job features are similar. One must note, that the figures are estimated from the entire sample of standard students, and there may be considerable individual differences in how either money, or specific locations, are valued.

Table 5 Valuations of job attribute levels per month in relation to base category (rupees)

\begin{tabular}{lcc}
\hline & Standard students & Para-teachers \\
\hline Location: Village / Small Town & $4430[580]$ & $4407[926]$ \\
Location: Home village / town & $7896[482]$ & $5624[670]$ \\
Location: District capital area & $4922[564]$ & $623[809]$ \\
Contract: Permanent, with rotation & $4212[486]$ & $4836[826]$ \\
Contract: Permanent & $5683[476]$ & $5793[728]$ \\
Transfers: Based on merit & $8138[422]$ & $6429[590]$ \\
Pupils and staff: 2 teachers, 14 pupils & $-494[326]$ & $-1492[558]$ \\
\hline
\end{tabular}

Notes: 1 USD $\sim 45$ Rupees. Standard errors in brackets. Calculated from the precise coefficients (not rounded to 3 digits as in Table 4). The estimated valuations are expressed in relation to the base categories, which are: (1) Location: Remote village, (2) Contract: Fixed term contract, renewable every 7 years, (3) Transfers: Based on connections and influence, (4) Pupils and staff: 2 teachers, 75 pupils.

In Table 5, the estimated monetary equivalents of different contract features have been computed for both normal, and para-teachers. These sums can be considered as guidelines on the monthly monetary value of generally more attractive job features, and consequently indicate how much less could teachers be paid for a job with a specific attractive feature. Standard errors are not calculated, but this shows that in monetary terms, both types of students value merit-based transfers most, followed by home village location and permanent contracts without rotation.

\section{Robustness checks}

This section reports on a set of robustness checks regarding the estimations. The first check relates to the selection of para-teachers into the training programme. The second one concerns consistency checks regarding the discrete choice experiment.

Para-teachers were selected mainly on the basis of teaching experience, but other characteristics, such as education, potentially also mattered. Therefore, there may be a 
concern that the para-teachers who were selected to the training programme and are included in our sample, do not represent well the population of para-teachers in the Uttarakhand state. To investigate this further, we compare the characteristics of para-teachers in our sample (Table 2) with the characteristics of para-teachers in the Uttarakhand state on average. The data on the latter are obtained from the District Information System on Education (DISE), which is a register database and by now covers well public sector primary schools across India. However, it only includes a limited number of teacher characteristics.

Overall, with respect to age and gender, the para-teachers in the survey sample do not differ from the para-teachers in the state as a whole. In the survey sample, the average birth year of para-teachers is 1977.7 (Table 2), implying that in 2010, para-teachers were on average 32 years old. The 2008-2009 DISE data suggest (Table 6) that the average age of para-teachers in government primary schools is 31.2 . In the survey sample, $50 \%$ of the parateachers are women and all hold a university degree. In the state as a whole $44 \%$ are women and $82 \%$ have degrees. Thus, it appears that education has been a factor in the selection process to the training programme, but the differences with respect to age and gender are very minor.

Table 6 Average characteristics of regular and para-teachers currently employed in government primary schools in Uttarakhand

\begin{tabular}{lccc|ccc} 
& \multicolumn{3}{c}{ Normal teachers } & \multicolumn{3}{c}{ Para-teachers } \\
& Obs. & Mean & S.D. & Obs. & Mean & S.D. \\
\hline Age & 58375 & 40.53 & 10.48 & 4143 & 31.15 & 6.16 \\
Female & 60168 & .46 & .50 & 4214 & .44 & .50 \\
Graduate & 59889 & .78 & .41 & 4212 & .82 & .38 \\
\hline
\end{tabular}

Notes: Source: DISE 2008-2009. The number of observations vary by variable due to missing observations

Table 7 below reports the results of a number of estimations, which can be compared with the main results, originally shown in column 1 of Table 4, but also replicated in Column 1 of Table 7. If for any reason, for instance due to the order of placement on the questionnaire, respondents would have a tendency to choose the A option in the DCE either with higher, or lower, probability, the results could be biased. This can be easily tested by including a constant in the model. Model 1 in Table 7 shows that a constant is not statistically significant and does not affect the results. 
Table 7 Robustness checks of the DCE Model

\begin{tabular}{|c|c|c|c|c|}
\hline & $\begin{array}{c}{[1]} \\
\text { Base model }\end{array}$ & $\begin{array}{c}\quad[2] \\
\text { Constant } \\
\text { included }\end{array}$ & $\begin{array}{c}{[3]} \\
\text { Excluding } \\
\text { lexicographic }\end{array}$ & $\begin{array}{c}{[4]} \\
\text { Teaching } \\
\text { experience }>\mathbf{1}\end{array}$ \\
\hline \multicolumn{5}{|l|}{ Contract attributes } \\
\hline Pay (1000 Rs) & $.129[.008]^{* *}$ & $.122[.009]^{* *}$ & $.138[.008]^{* *}$ & $.115[.012]^{* *}$ \\
\hline Location: Village / Small Town & $.573[.065]^{* *}$ & $.507[.077]^{* *}$ & $.649[.070] * *$ & $.461[.100]^{* *}$ \\
\hline Location: Home village / town & $1.021[.068]^{* *}$ & $.993[.070]^{* *}$ & $1.141[.076]^{* *}$ & $.800[.102]^{* *}$ \\
\hline Location: District capital area & $.636[.067]^{* *}$ & $.564[.081]^{* *}$ & $.715[.072]^{* *}$ & $.520[.103]^{* *}$ \\
\hline Contract: Permanent, with rotation & $.545[.047]^{* *}$ & $.546[.047]^{* *}$ & $.639[.050]^{* *}$ & $.710[.071]^{* *}$ \\
\hline Contract: Permanent & $.735[.070]^{* *}$ & $.710[.072]^{* *}$ & $.820[.077] * *$ & $.792[.107]^{* *}$ \\
\hline Transfers: Based on merit & $1.052[.052]^{* *}$ & $1.034[.054]^{* *}$ & $.923[.057] * *$ & $1.133[.080]^{* *}$ \\
\hline Small class size & $-.064[.041]$ & $-.085[.043]^{*}$ & $-.019[.044]$ & $-.108[.063]+$ \\
\hline \multicolumn{5}{|l|}{ Interaction terms } \\
\hline Para × Pay $(1000 \mathrm{Rs})$ & $-.029[.012]^{*}$ & $-.029[.012]^{*}$ & $-.034[.013]^{* *}$ & $-.013[.015]$ \\
\hline Para $\times$ Village $/$ Small Town & $-.129[.104]$ & $-.125[.104]$ & $-.145[.110]$ & $-.022[.131]$ \\
\hline Para $\times$ Home village / town & $-.455[.105]^{* *}$ & $-.455[.105]^{* *}$ & $-.513[.113]^{* *}$ & $-.217[.132]$ \\
\hline Para $\times$ District capital area & $-.574[.105]^{* *}$ & $-.573[.105]^{* *}$ & $-.608[.112]^{* *}$ & $-.451[.134]^{* *}$ \\
\hline Para $\times$ Permanent, with rotation & $-.058[.074]$ & $-.057[.074]$ & $-.081[.079]$ & $-.198[.094]^{*}$ \\
\hline Para $\times$ Permanent & $-.151[.108]$ & $-.157[.109]$ & $-.181[.116]$ & $-.156[.138]$ \\
\hline Para $\times$ Based on merit & $-.405[.081] * *$ & $-.406[.081]^{* *}$ & $-.344[.087]^{* *}$ & $-.485[.104]^{* *}$ \\
\hline Para $\times$ Small class size & $-.086[.064]$ & $-.082[.065]$ & $-.135[.068]^{*}$ & $-.069[.082]$ \\
\hline Constant & & $-.063[.040]$ & & \\
\hline Observations & 8198 & 8198 & 7190 & 5053 \\
\hline
\end{tabular}

**,*,+ : significant at the $1 \%, 5 \%$ and $10 \%$ levels respectively.

One potential disadvantage of discrete choice experiments in relation to contingent valuation is the cognitive complexity of the task for the respondents. It is possible that to simplify the task, some respondents use rules of thumb, such as lexicographic ordering, to make their choices (Hanley et al., 2001). Model 2 in Table 7 excludes a subset of respondents for whom we find lexicographic preferences, i.e. that they always prefer a certain contract attribute. This could also reflect strategic behaviour. As documented in Appendix 3, the tendency to exhibit such a preference is strongest regarding the "merit-based transfers" option; 57 respondents always choose a contract with this attribute when it's an option. Strict preferences for other attributes were much less frequent. Lancsar and Louviere (2006) argue against deleting respondents with lexicographic preferences, since theoretically, a random utility model may be able to cope with such preferences, and information is being lost. In our case, the estimates remain qualitatively very similar when individuals with lexicographic preferences are removed from the sample.

There may also be a concern that the fact that para-teachers have more teaching 
experience significantly alters their job preferences. The regression models do control for experience to an extent (Models 3-4, Table 4), but Model 3 in Table 7 is a direct attempt to address the issue, by only including students who have at least one year of teaching experience. This selection should exclude some of those standard students who have the most naïve perceptions about teaching as a profession, and affect the results accordingly. Two minor differences in results may be worth pointing out. Firstly, the valuation of the Home village/town location for declines for standard students to an extent. Secondly, the valuation of a permanent contract with rotation increases among standard students to such extent that the difference to para-teachers becomes significant. As already speculated, it is possible that teaching experience, which has probably taken place in their home town, makes teachers value occasional change in location.

There may be a concern that the mountainous nature of Uttarakhand makes it an unrepresentative state in India and that this may affect the results, especially with respect to how different geographic locations are valued. This is addressed in Table 8, which shows the results of estimates for the basic model with separate sub-samples for lowland districts (Haridwar, Dehradun, Udham Singh Nagar) and hill districts (Rudraprayag, Chamoli, Almora, Nainital). The consistency of results across the sub-samples is surprisingly strong. If anything, it appears that in the lowlands, which are geographically more representative of India in general, standard students are more averse to remote locations as evidenced by larger coefficients for the alternatives. Overall, the differences between the preferences of parateachers and standard students are more pronounced, suggesting a starker trade-off in preferences, and possibly motivation. 
Table 8 DCE Estimates, lowland versus mountain districts

\begin{tabular}{|c|c|c|}
\hline & $\begin{array}{c}{[1]} \\
\text { Lowland } \\
\text { districts }\end{array}$ & $\begin{array}{c}{[2]} \\
\text { Mountain } \\
\text { districts }\end{array}$ \\
\hline \multicolumn{3}{|l|}{ Contract attributes } \\
\hline Pay (1000 Rs) & $.141\lceil .012\rceil^{* *}$ & $.123[.010]^{* *}$ \\
\hline Location: Village / Small Town & $.687[.100]^{* *}$ & $.488[.086]^{* *}$ \\
\hline Location: Home village / town & $1.374[.113]^{* *}$ & $.792[.086]^{* *}$ \\
\hline Location: District capital area & $.784[.105]^{* *}$ & $.532[.088]^{* *}$ \\
\hline Contract: Permanent, with rotat & $.564[.072]^{* *}$ & $.531[.062]^{* *}$ \\
\hline Contract: Permanent & $.908\lceil .115\rceil^{* *}$ & $.640[.089]^{* *}$ \\
\hline Transfers: Based on merit & $1.133[.083\rceil^{* *}$ & $1.010[.068]^{* *}$ \\
\hline Small class size & $-.093[.063]$ & $-.039[.054]$ \\
\hline \multicolumn{3}{|l|}{ Interaction terms } \\
\hline Para $\times$ Pay $(1000$ Rs $)$ & $-.036[.019]+$ & $-.025[.016]$ \\
\hline Para $\times$ Village / Small Town & $-.172[.158]$ & $-.101[.139]$ \\
\hline Para $\times$ Home village $/$ town & $-.684[.165\rceil^{* *}$ & $-.324[.137]^{*}$ \\
\hline Para $\times$ District capital area & $-.606[.161\rceil^{* *}$ & $-.564[.140]^{* *}$ \\
\hline Para $\times$ Permanent, with rotation & $-.176\lceil .113\rceil$ & $.037[.099]$ \\
\hline Para $\times$ Permanent & $-.382[.169]^{*}$ & $-.009[.143]$ \\
\hline Para $\times$ Based on merit & $-.485\lceil .125\rceil^{* *}$ & $-.361[.108]^{* *}$ \\
\hline Para $\times$ Small class size & $-.099\lceil .098\rceil$ & $-.076[.086]$ \\
\hline \multicolumn{3}{|l|}{ Constant } \\
\hline Observations & 3583 & 4615 \\
\hline
\end{tabular}

Notes: $* *,{ }^{*},+$ : significant at the $1 \%, 5 \%$ and $10 \%$ levels respectively. Lowland districts are Haridwar, Dehradun and Udham Singh Nagar. Mountain districts are Rudraprayag, Chamoli, Almora, and Nainital.

\section{Conclusions}

Attracting qualified public sector workers to remote locations is a universal challenge for developing, as well as many developed countries. One common policy with respect to teachers, growing in importance in India and elsewhere, is to hire educated locals to run schools in remote places on a contract basis, even if their selection may be based on less stringent criteria.

The use of para-teachers has remained controversial in India, and little is still known about their relative effectiveness, motivation and skills with respect to regular, trained teachers. The few existing studies on the effects of these teachers on pupil outcomes suggest that current para-teachers in schools do not under-perform, and can even outperform existing regular teachers. Some studies also find that para-teachers are absent less often. However, this evidence is still limited and there is little firm evidence on possible reasons for these differences. 
By carrying out a Discrete Choice Experiment relating to job preferences and testing for skills, this study offers a new perspective to the differences between para-teachers and regular teachers and their potential effectiveness. The measurement of both preferences and skills is bound to be controversial and dependent on assumptions, but they are both likely to be of significance for policy formulation.

In the Discrete Choice Experiment, respondents are repeatedly presented with alternative job contracts with different levels of job attributes, and are asked to choose the ones they prefer. Following a random utility framework common to modelling of discrete choice, the responses are explained with a Logit model, and the estimated parameters interpreted as marginal contributions of the contract attribute levels to the utility of respondents.

The study reveals significant differences both in the job preferences, as well as skills, of para-teachers and competitively selected students bound for a career in teaching. With respect to preferences, a key difference that stands out relates to preferred location. Parateachers do not value the district capital any more than a remote village as a place of employment, whereas the standard students value the district capital significantly more. Both types of students have a strong preference to work in their home village, or town, in relation to all other options, but this preference is weaker for para-teachers. In short, para-teachers, who almost all come from rural areas, prefer rural areas in general and standard teachers less so. Higher pay and a permanent contract are valued significantly by both. However, the standard students value pay somewhat more and as opposed to para-teachers, have a stronger preference for permanent contracts without rotation as opposed to permanent contracts with rotation. Whereas standard students are indifferent with respect to class size, para-teachers actually prefer larger class size. Some, but not much of the differences can be explained by "life-cycle" factors in which the two groups tend to differ, namely years of experience and numbers of children. Instead, differences in home location, education and skills appear to explain the bulk of the differences in the preferences between the two groups.

In terms of our primary skills measure, para-teachers perform on average 0.74 standard deviations worse than the standard students selected in a competitive written test. This is a large difference. The differences between the two groups were particularly apparent in arithmetic computations. This finding corresponds with results from the SchoolTELLS survey, which measured teachers' subject skills in relation to the expected level required from 
the students (see e.g. Banerji and Kingdon, 2010).

A key implication of the results is that the use of local para-teachers is likely to include a considerable trade-off between general skills and the willingness and motivation to work in a more remote location. On the other hand, the variation in skills was broad in both groups. Whether, and to what extent, the differences in these skills translate into better, or worse, teaching at the primary level may be difficult to assess, but it is unlikely that the differences are irrelevant.

As a counterbalance to lower skills on average, para-teachers have preferences that might help them adapt better to more difficult locations. Individuals who enter the teaching profession from rural areas as contract teachers on average differ from individuals who are selected via examinations to gain a public sector job. Our findings on preferences suggest that para-teachers are likely to be more motivated in remote and disadvantaged areas, on contracts that may involve rotation between locations and possibly even with large class sizes. They may therefore be more content with the type of employment available on average in the public primary school system in Uttarakhand, and around India. The DISE data for 2008 show that $94 \%$ of public sector primary schools in India are in rural locations.

The results suggest that the traditional route of hiring individuals competitively for permanent civil service jobs may not succeed in attracting individuals who have an inclination towards the social-service nature of primary education in large parts of India. A few of the existing studies on the effects of contract teachers suggest that their impact is to reduce inequalities in performance. This may reflect their own experiences of growing up in remote areas. One recent piece of research that stresses the role that connectedness plays in student attainment is by Rawal and Kindgon (2010), who show that in Bihar and Uttar Pradesh students do better when taught by a teacher who shares their gender, religion and caste.

The stark trade-off between skills and preferences observed in this study, points to a few possible policy solutions, the success of which may vary depending on circumstances:

1. If recruitment were to rely entirely on regular teachers selected through competitive examinations, compensatory payment might raise the attractiveness of remote areas. Our estimates suggest that a standard student should be paid approximately 5,000 rupees more per month to induce him, or her, to voluntarily take up a position in a remote village as opposed to a position in the district capital. However, given that in Uttarakhand the starting salary of primary school teachers is approximately 18,000 rupees, this is a significant amount. 
2. Further decentralisation in hiring. Currently in Uttarakhand, teachers hired to work in a particular district, have to be residents of that district. Typically all districts have a (desirable) urban centre, and large (undesirable) rural areas. A further decentralisation in hiring could improve the geographic match of teachers, but could also lead to lower average skill levels, unless the screening of skills in hiring is improved.

3. If the recruitment of para-teachers would continue, the results suggest a need for upgrading skills of such teachers. If effective, training may improve the general skill level of para-teachers and narrow the trade-off between skills and preferences. However, it is possible that improved skills alter preferences. Whilst the recruitment of para-teachers would be more cost-effective, and might allow for more teachers, it is politically sensitive.

\section{References}

Adamowicz, W., Louviere J. and Williams, M. (1994) Combining Revealed and Stated

Preference Methods for Valuing Environmental Amenities. Journal of Environmental Economics and Management, 26(3), 271-292.

Atherton, P. and Kingdon, G. (2010) The Relative Effectiveness and Costs of Contract and Regular Teachers in India. Centre for the Study of African Economies Working Paper 15, University of Oxford.

Banerjee, A.V., Banerji, R, Duflo E., Glennerster R., and Khemani, S. (2010) Pitfalls of Participatory Programs: Evidence From a Randomized Evaluation in Education in India. American Economic Journal: Economic Policy, 2(1), 1-30.

Banerji, R. and Kingdon, G. (2010) How Sound are Our Mathematics Teachers? Insights from the SchoolTELLS Survey. Learning Curve. A Newsletter from Azim Premji Foundation, March.

Béteille, T. (2009) Absenteeism, Transfers and Patronage: The Political Economy of Teacher Labor Markets in India. Executive summary of PhD dissertation, Stanford University. 
Bourdon, J., Frölich, M. and Michaelowa K. (2010) Teacher Shortages, Teacher Contracts, and Their Effects on Education in Africa. Journal of the Royal Statistical Society: Series A, 173(1), 93-116.

Chomitz, K.M., Setiadi, G., Azwar, A. and Widiyarti N.I. (1998) What Do Doctors Want? World Bank Policy Research Working Paper 1888.

De Laat, J. and Vegas E. (2005) Do Differences in Teacher Contracts Affect Student Performance? Evidence from Togo. Unpublished mimeo, Department of Economics, Brown University.

Diamond, P.A. and Hausman, J.A. (1994) Contingent Valuation: Is Some Number Better than No Number? The Journal of Economic Perspectives, 8(4), 45-64.

Duflo, E., Hanna R., and Ryan S.P. (2010) Incentives Work: Getting Teachers to Come to School. CEPR Discussion Paper 6682.

Duflo, E., Dupas P., and Kremer, M. (2009) Additional Resources versus Organizational Changes in Education: Experimental Evidence from Kenya. Unpublished mimeo, Department of Economics, MIT, 2009.

Glewwe, P., Kremer M., and Ilias, N. (2010) Teacher Incentives. American Economic Journal: Applied Economics, 2(3), 205-27.

Godiyal, S., and Nautiyal, R.C. (2008) Status of Teacher Education in Uttarakhand. E-journal of All India Association for Educational Research, 20(1-2).

Govinda, R. and Josephine, Y. (2004) Para Teachers in India: A Review. UNESCO, Paris.

Goyal, S, and Pandey, P. (2009) Contract Teachers. Report 28, South Asia Human Development Sector, World Bank. 
Guttman, R., Castle R., and Fiebig, D.G. (2009) Use of Discrete Choice Experiments in Health Economics: An Update of the Literature. CHERE Working Paper 2009/2, University of Technology, Sydney.

Hanley, N., Mourato S., and Wright, R.E. (2001) Choice Modelling Approaches: A Superior Alternative for Environmental Valuation? Journal of Economic Surveys, 15(3), 435-62.

Hanson, K. and Jack, W. (2010) Designing Incentives for Rural Health Workers. In Incentives and Dynamics in the Ethiopian Health Worker Labour Market (ed. W. Jack, J. de Laat, K. Hanson and A. Soucat), World Bank.

Huber, J., and Zwerina, K. (1996) The Importance of Utility Balance in Efficient Choice Designs. Journal of Marketing Research, 33(3), 307-317.

Kingdon, G. and Teal, F. (2007) Does Performance Related Pay for Teachers Improve Student Achievement? Evidence from India. Economics of Education Review, 26(4), 473-86.

Kingdon, G. (2010) The Impact of the Sixth Pay Commission on Teacher Salaries: Assessing Equity and Efficiency Effects. RECOUP Working Paper 29.

Kingdon, G. and Sipahimalani-Rao, V. (2010) Para-Teachers in India: Status and Impact. Economic and Political Weekly, 45(12), 20-26.

Kolstad, J.R. (2011) How to Make Rural Jobs Attractive to Health Workers. Findings from a Discrete Choice Experiment in Tanzania. Health Economics, 20(2), 196-211.

Kremer, M., Muralidharan, K., Chaudhury N., Hammer, J. and Rogers, F.H. (2005) Teacher Absence in India: A Snapshot. Journal of the European Economic Association, 3(2-3), 658667.

Lagarde, M. and Blaauw, D. (2009) A Review of the Application and Contribution of Discrete Choice Experiments to Inform Human Resources Policy Interventions. Human Resources for 
Health, 7(62).

Lancsar, E. and Louviere, J. (2006) Deleting 'Irrational' Responses from Discrete Choice Experiments: A Case of Investigating or Imposing Preferences? Health Economics, 15(8), 797-811.

Lusk, J.L., and Norwood, F.B. (2005) Effect of Experimental Design on Choice-based Conjoint Valuation Estimates. American Journal of Agricultural Economics, 87(3), 771-785.

Mangham, L. and Hanson, K. (2008). Employment Preferences of Public Sector Nurses in Malawi: Results from a Discrete Choice Experiment. Tropical Medicine \& International Health, 13(12), 1433-1441.

Mangham, L., Hanson K., and McPake, B. (2009) How to do (or not to do) ... Designing a Discrete Choice Experiment for Application in a Low-Income Country. Health Policy and Planning, 24(2), 151-8.

McFadden, D. (1974) Conditional Logit Analysis of Qualitative Choice Behavior. In Frontiers in Econometrics, (ed. P. Zarembka), 105-142. Academic Press, New York.

Metzler, J., and Woessman L. (2010) The Impact of Teacher Subject Knowledge on Student Achievement. Evidence from Within Teacher Within Student Variation. IZA Discussion Paper 4999.

Muralidharan, K., and Sundararaman, V. (2011) Teacher Performance Pay: Experimental Evidence from India. Journal of Political Economy, 119(1), 39-77.

Muralidharan, K. and Sundararaman, V. (2010). Contract Teachers: Experimental Evidence from India. Unpublished mimeo, University of San Diego, Department of Economics.

Pandey, S. (2006) Para-teacher scheme and quality education for all in India: policy perspectives and challenges for school effectiveness. Journal of Education for Teaching: 
International Research and Pedagogy, 32(3), 319-334.

Pandey, S., and Rani R. (2003) Professional Support Systems and Classroom Performance of Para Teachers. NCERT, New Delhi.

Penn-Kekana, L., Blaauw D., Tint, K.S., Monareng, D., and Chege, J. (2005) Nursing Staff Dynamics and Implications for Maternal Health Provision in Public Health Facilities in the Context of HIV/AIDS. Report for Frontiers in Reproductive Health Program, Population Council.

Ramachandran, V., Pal, M., Jain, S., Shekar, S., and Sharma, J. (2005) Teacher Motivation in India. Educational Research Unit.

Ramachandran, V. (2009) What is 'Para' about Some Teachers? Report for Educational Research Unit, Delhi.

Ratcliff, G., Ganguli, M., Chandra, V., Sharma, S., Belle, S., Seaberg, E., and Pandav, R. (1998) Effects of Literacy and Education on Measures of Word Fluency. Brain and Language, 61(1), 115-122.

Rawal, S., and Kingdon, G. (2010) Akin to My Teacher. Does Caste, Religious and Gender Distance Between Student and Teacher Matter? Some Evidence from India. Department of Quantitative Social Science Working Paper 10-18, Institute of Education, University of London.

Rosselli, M., Ardila, A., Salvatierra, J., Marquez, M., Matos L., and Weekes, V.A. (2002) A cross-linguistic comparison of verbal fluency tests. International Journal of Neuroscience, 112(6), 759-776.

Serneels P., Lindelöw, M., Garcia-Montalvo, J., and Barr, A. (2005) For Public Service or Money Understanding Geographical Imbalances in the Health Workforce. Health Policy and Planning, 22(3), 128-138. 
Serneels, P., Garcia-Montalvo, J., Pettersson, G., Lievens, T., Butera, J.D., and Kidanu, A. (2010) Who Wants to Work in a Rural Health Post? The Role of Intrinsic Motivation, Rural Background and Faith-Based Institutions in Ethiopia and Rwanda. Bulletin of the World Health Organisation, 88(5), 342-349.

Sharma, R. (1999) What Manner of Teacher - Some Lessons from Madhya Pradesh. Economic and Political Weekly, 34(25), 1597-1607.

Street, D.J., Burgess, L., and Louviere, J.J. (2005) Quick and Easy Choice Sets: Constructing Optimal and Nearly Optimal Stated Choice Experiments. International Journal of Research in Marketing, 22(4), 459-470.

Thurstone, L.L. (1938) Primary Mental Abilities. University of Chicago Press, Chicago.

WHO (2006) World Health Report 2006: Working Together for Health. World Health Organization, Geneva.

Wibulpolprasert, S., and Pengpaibon, P. (2003). Integrated Strategies to Tackle the Inequitable Distribution of Doctors in Thailand: Four Decades of Experience. Human Resources for Health, 1(12). 


\section{Appendix 1 Data collection}

The research team visited the teacher training centres (DIETs) of 7 districts out of 13 in the state in May 2010 (see Figure A1). 120 survey questionnaires were printed for each school with the aim of randomly sampling $50 \%$ of both standard students and para-teachers from each district, or having roughly 50 para-teachers and 50 standard students from each district. Table A1 shows the final sample sizes, and how the randomisation of students was carried out.

Figure A1 Sampled districts of Uttarakhand

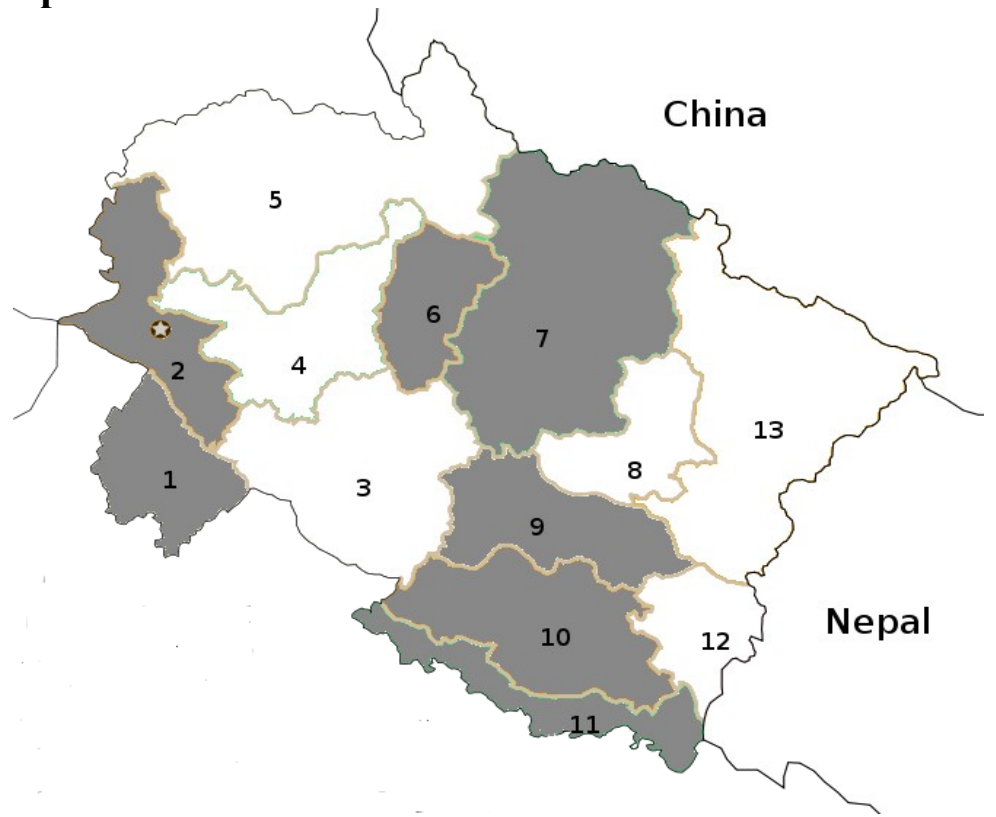

Notes: The sampled districts are shaded. (1) Haridwar, (2) Dehradun, (3) Tehri Garhwal , (4) Tehri, (5) Uttarkashi, (6) Rudraprayag, (7) Chamoli, (8) Bageshwar, (9) Almora, (10) Nainital, (11) Udham Singh Nagar, (12) Champawat, (13) Pithoragarh. Map source: Wikimedia Commons. GNU Free Documentation Licence.

\section{District Information System Data (DISE)}

Data on schools or teachers of Uttarakhand referred to, was obtained from the DISE 20082009 database. The data was provided by National University of Educational Planning and Administration in Delhi (NUEPA). 
Table A1 Sample size and notes on data collection

\section{Sample sizes}

Standard Para-

District students teachers Randomisation

Notes on conditions

\begin{tabular}{lllll} 
Almora & 43 & 49 & $\begin{array}{l}50 \% \text { of both groups randomised } \\
\text { from student register. }\end{array}$ & Chairs, but no tables. \\
\hline Chamoli & 62 & 56 & $\begin{array}{l}\text { Questionnaires distributed in } \\
\text { classrooms in random fashion. }\end{array}$ & $\begin{array}{l}\text { Standard students had } \\
\text { chairs, no tables. Para- } \\
\text { teachers sat on the } \\
\text { floor. }\end{array}$ \\
\hline Dehradun & 51 & 41 & $\begin{array}{l}50 \% \text { of both groups randomised } \\
\text { from student register. }\end{array}$ & $\begin{array}{l}\text { Most students had } \\
\text { chairs and tables, some } \\
\text { just chairs. }\end{array}$
\end{tabular}
Haridwar $63 \quad 43 \begin{aligned} & 50 \% \text { of both groups randomised by staff, } \\ & \text { criteria unknown. }\end{aligned}$

Nainital

50

47

$50 \%$ of both groups randomised by staff, criteria unknown.

Chairs and tables.

All standard students present were

Rudraprayag $86 \quad 0 \quad$ included. Only 8 para-teachers enrolled in Chairs, but no tables. the school, and thus not covered.

All standard students present were

\begin{tabular}{llll}
$\begin{array}{l}\text { Udham } \\
\text { Singh Nagar }\end{array}$ & 71 & 42 & $\begin{array}{l}\text { included, and half of para-teachers covered Chairs and tables. } \\
\text { (one randomly selected classroom out of } \\
\text { two). }\end{array}$ \\
\hline
\end{tabular}

$\begin{array}{lll}\text { Total } & 426 & 278\end{array}$




\section{Appendix 2 Skills tests}

As part of the survey, the teacher students filled a three-part timed skills test. The parts are referred to here as Countries, English and Arithmetic. The test was designed so that it would not consume much time and would be easy to implement in different conditions, fast to mark, and would leave as little room as possible for cheating. Questionnaires were bilingual (English+Hindi), and instructions were given in English and Hindi prior to each skill test.

In the 'Countries' test, the students had to write down as many countries as they could in 90 seconds. They could use any language they wished, and most used Hindi, while some used English. The students were not told that they should write down the names of countries prior to the beginning of the test, but simply "items from an announced category". An example using animals was given. The scoring of the test was based on the number of items written down, regardless of whether they were real countries or not. ${ }^{15}$ The average score across 704 responses was 16.03, with a standard deviation of 4.4 and a range of 3 to 33 . The 'Countries' test would be classified in research literature as a test of semantic fluency. The origins of such a test can be traced to Thurstone's Word Fluency Test for verbal ability (Thurstone, 1938). It may be useful in examination of, for example, language, executive functioning, and speed of information processing. It has been found that education and age have an impact on the number of items written down, whereas gender usually has only a small effect (Ratcliff et al. 1998). In our context, this can be seen as a test of general knowledge, verbal skills, and a proxy for the quality of education.

In the 'English' test, the students had to first write down as many English words beginning with an "F" as they could in 60 seconds, and next, as many beginning with an "S" as they could in 60 seconds. The scoring was based on the average number of proper nouns for the two letters, allowing for minor spelling mistakes. Numbers only up to 10 ('Four', 'Five', 'Six', 'Seven') were accepted. The correlation between the two sets of produced words was 0.74 across 702 respondents. The average combined score was 9.96 with a standard deviation of 3.82. Further details are shown in Table A2 below. The 'English' test has a similar origin as the 'Countries' test as a measure of verbal fluency, but it is typically applied to people in their native language. As in our case virtually all respondents are native Hindi speakers, the tests serve as an ad-hoc test for English vocabulary (for discussion on monoand bilingual respondents, see Rosselli et al. 2002).

Table A2 Scores for the English vocabulary tests.

\begin{tabular}{lccccc} 
& Obs. & Mean & S.D. & Min & Max \\
\hline English-F & 702 & 10.28 & 3.9 & 0 & 24 \\
English-S & 704 & 9.62 & 4.29 & 0 & 24 \\
\hline Average & 702 & 9.96 & 3.82 & 0 & 22 \\
\hline
\end{tabular}

Notes: Correlation of $\mathrm{F}$ and $\mathrm{S}$ scores is 0.7364 , with 702 observations.

The 'Arithmetic' test consisted of 40 calculations based on addition, subtraction, multiplication and division, at an increasing order of difficulty. The problems should be relatively easy for a person who is familiar with and seasoned in arithmetic computations, such as primary school teachers. The respondents were given 4 minutes to answer as many as

\footnotetext{
${ }^{15}$ This scoring method was based on convenience of not having to go through hundreds of responses in two languages. Based on responses given in English, this does not appear to be a concern - only a few respondents gave occasional responses that were not actual countries, such as "Rome" or "Taliban".
} 
they could. They were not allowed to use a calculator, but could use scrap paper and a pen to perform the calculations. The average number of solved calculations for 696 responses was 27.71 with a standard deviation of 8.64. The scores ranged from 3 to 40.16 respondents achieved the full score of 40 .

Table A3 Summary scores of the three skills components

\begin{tabular}{lccccc} 
& Obs. & Mean & S.D. & Min & Max \\
\hline Countries & 704 & 16.04 & 4.4 & 3 & 33 \\
English & 702 & 9.96 & 3.82 & 0 & 22 \\
Arithmetic & 696 & 27.71 & 8.64 & 3 & 40 \\
\hline
\end{tabular}

Table A4 Correlations over the skills measures $(0 b s=694)$

\begin{tabular}{l|cc} 
& Countries & English \\
\hline English & .40 & \\
Arithmetic & .47 & .51
\end{tabular}

A principal component analysis of the skill measures was carried out. The first principal component was constructed and normalised to have a mean of zero and a standard deviation of one. This is the primary measure of skills used in the paper.

Table A5 Correlation of the $1^{\text {st }}$ principal component with the tests

\begin{tabular}{lc}
\multicolumn{1}{c}{ Subtest } & Correlation with 1st PC \\
\hline Arithmetic & .83 \\
English & .80 \\
Countries & .77 \\
\hline
\end{tabular}




\section{Appendix 3 Design of the Discrete Choice Experiment}

In this study the job contracts have five attributes, and the attributes have two to four levels as follows: a) Pay: 0 - "Rs. 13000 per month", 1 - "Rs. 17000 per month", 2 - "Rs. 21000 per month". b) Location: 0 - "Remote village", 1 - "Village / Small town", 2 - "Your home village / town", 3 - "District capital area". c) Contract: 0 - "Fixed term contract, renewable every 7 years", 1 - "Permanent, must transfer every 7 years, 2 - "Permanent, possibility to transfer after 7 years". d) Transfers: 0 - "Depend on connections and influence", 1 - "Depend on merit". e) Staff and pupils: 0 - "2 teachers, 14 pupils", 1 - " 2 teachers, 75 pupils".

These attributes and levels were chosen after consulting a number of academics and policy makers in Delhi, as well as officials in states of Uttarakhand, Himachal Pradesh and Punjab, many of whom were former teachers.

Thus, there are total of 144 possible contracts arising from combinations $\{\mathrm{a} 0, \mathrm{a} 1, \mathrm{a} 2\} \times$ $\{\mathrm{b} 0, \mathrm{~b} 1, \mathrm{~b} 2, \mathrm{~b} 3\} \times\{\mathrm{c} 0, \mathrm{c} 1, \mathrm{c} 2\} \times\{\mathrm{d} 0, \mathrm{~d} 1\} \times\{\mathrm{e} 0, \mathrm{e} 1\}$. Further, there are a total of $(144 \times 144-$ $144) / 2=10296$ possible contract pair comparisons.

Out of the 10296 possible contract pairs, 12 pairs were selected using the principles from the literature on DCEs. Mangham et al. (2008) provide a practical primer, whereas a good theoretical starting point is Street, Burgess and Louviere (2005).

Out of the 144 possible contracts (full factorial), a fractional factorial of 24 contracts is first selected. This is a sub-group for which the levels of attributes are orthogonal. These 24 contracts are shown in Table A6. An orthogonal fractional factorisation guarantees two desirable properties for the DCE: Orthogonality - attributes of the design are independent of each other, and level balance - that each attribute level appears in the design with equal likelihood (Mangham et al., 2008).

Combining the 24 contracts into 12 pairs randomly should produce unbiased estimates of the $\beta$ and $\delta$ parameters in equation 4 . However, random pairing is likely to produce a design with low efficiency, or larger than necessary standard errors for the estimated parameters.

Table A6 Orthogonal 24-fractional factorial. Contract number and attribute levels.

\begin{tabular}{|c|c|c|c|c|c|c|c|c|c|c|c|}
\hline Contract number & \multicolumn{5}{|c|}{ Attributes } & Contract number & \multicolumn{5}{|c|}{ Attributes } \\
\hline & $\mathrm{a}$ & $\mathrm{b}$ & $\mathrm{c}$ & $\mathrm{d}$ & e & & $\mathrm{a}$ & $\mathrm{b}$ & $\mathrm{c}$ & $\mathrm{d}$ & e \\
\hline 1 & 0 & 0 & 1 & 0 & 0 & 13 & 0 & 2 & 1 & 0 & 0 \\
\hline 2 & 0 & 0 & 1 & 1 & 1 & 14 & 0 & 2 & 1 & 1 & 1 \\
\hline 3 & 1 & 0 & 0 & 1 & 1 & 15 & 1 & 2 & 0 & 1 & 1 \\
\hline 4 & 1 & 0 & 2 & 0 & 0 & 16 & 1 & 2 & 2 & 0 & 0 \\
\hline 5 & 2 & 0 & 0 & 0 & 1 & 17 & 2 & 2 & 0 & 0 & 1 \\
\hline 6 & 2 & 0 & 2 & 1 & 0 & 18 & 2 & 2 & 2 & 1 & 0 \\
\hline 7 & 0 & 1 & 0 & 1 & 0 & 19 & 0 & 3 & 0 & 1 & 0 \\
\hline 8 & 0 & 1 & 2 & 0 & 1 & 20 & 0 & 3 & 2 & 0 & 1 \\
\hline 9 & 1 & 1 & 0 & 0 & 0 & 21 & 1 & 3 & 0 & 0 & 0 \\
\hline 10 & 1 & 1 & 2 & 1 & 1 & 22 & 1 & 3 & 2 & 1 & 1 \\
\hline 11 & 2 & 1 & 1 & 1 & 0 & 23 & 2 & 3 & 1 & 1 & 0 \\
\hline 12 & 2 & 1 & 1 & 0 & 1 & 24 & 2 & 3 & 1 & 0 & 1 \\
\hline
\end{tabular}


To improve the efficiency of the estimates, two further principles can be applied: Minimal overlap and utility balance (Huber and Zwerina, 1996). The former states that more information can be inferred with a DCE if the levels of attributes within a choice set are different (in our case between contracts A and B). The latter principle states that the efficiency can be improved by using some prior assumptions about the true parameters, and setting the choices within the choice set to have similar overall utility. It has also been argued that the techniques for improving the efficiency may not be very important as sample size can substitute for an inefficient experimental design (Lusk and Norwood, 2005).

In this study, 12 contract pairs (choice sets) were selected from the 24 contracts using an improvised 'Monte Carlo' type approach: The 24 contracts were combined into 12 matched pairs repeatedly by an algorithm that attempted to minimise the overlap of attribute levels between pairs. A set of the resulting "low-overlap" pairings (i.e. different sets of 12 pairs) was used to simulate choices for 500 respondents with identical utility functions but individual error terms (corresponding to the random utility model). ${ }^{16}$ These choices were then predicted with a Logit model, and the precision of the estimates was evaluated (the larger the determinant of the information matrix, the more precise).

The process led us to choose the following set of contract number pairings (Contract A, Contract B): $(16,5),(9,1),(24,7),(15,6),(10,17),(12,19),(22,18),(21,2),(4,14),(11,20)$, $(3,13),(23,8)$. Table A7 below shows the actual choices of the respondents. There were no pairs (choice sets) for which a certain option would have always been preferred (either only A, or only B).

Table A7 Frequency of choices in the DCE

\begin{tabular}{ccccc}
$(\mathbf{A}, \mathbf{B})$ & Choose $\mathbf{A}$ & Choose $\mathbf{B}$ & Non-response & \% Non-resp. \\
\hline$(16,5)$ & 514 & 172 & 21 & 3.1 \\
$(9,1)$ & 426 & 259 & 22 & 3.2 \\
$(24,7)$ & 421 & 267 & 19 & 2.8 \\
$(15,6)$ & 300 & 390 & 17 & 2.5 \\
$(10,17)$ & 484 & 202 & 21 & 3.1 \\
$(12,19)$ & 427 & 259 & 21 & 3.1 \\
$(22,18)$ & 176 & 511 & 20 & 2.9 \\
$(21,2)$ & 258 & 424 & 25 & 3.7 \\
$(4,14)$ & 204 & 476 & 27 & 4.0 \\
$(11,20)$ & 601 & 82 & 24 & 3.5 \\
$(3,13)$ & 315 & 362 & 30 & 4.4 \\
$(23,8)$ & 566 & 114 & 27 & 4.0 \\
\hline
\end{tabular}

We have tested for lexicographic preferences, and found that there were seven respondents who always chose the contract with higher pay, four who always chose the contract with the remotest place, four who always chose the contract with the least remote place, 57 who always based their chose on merit-based transfers, four who always chose the contract with small class size, and eight who always chose the contract with large class size. Further, there were three respondents who always chose the 'A' contract, and one who always chose 'B', which signals a very small number of clearly inconsistent choices.

\footnotetext{
${ }^{16}$ It was assumed that each level improvement within an attribute increases the utility by the same amount compared to the lower level (with reference to Equation 4, fixed term contract gets $\beta=1$, permanent with rotation gets $\beta=2$, Permanent without rotation $\beta=3$ and so on).
} 


\section{Appendix 4 Further Information}

Figure A2 Distribution the test scores and the $1^{\text {st }}$ principal component.
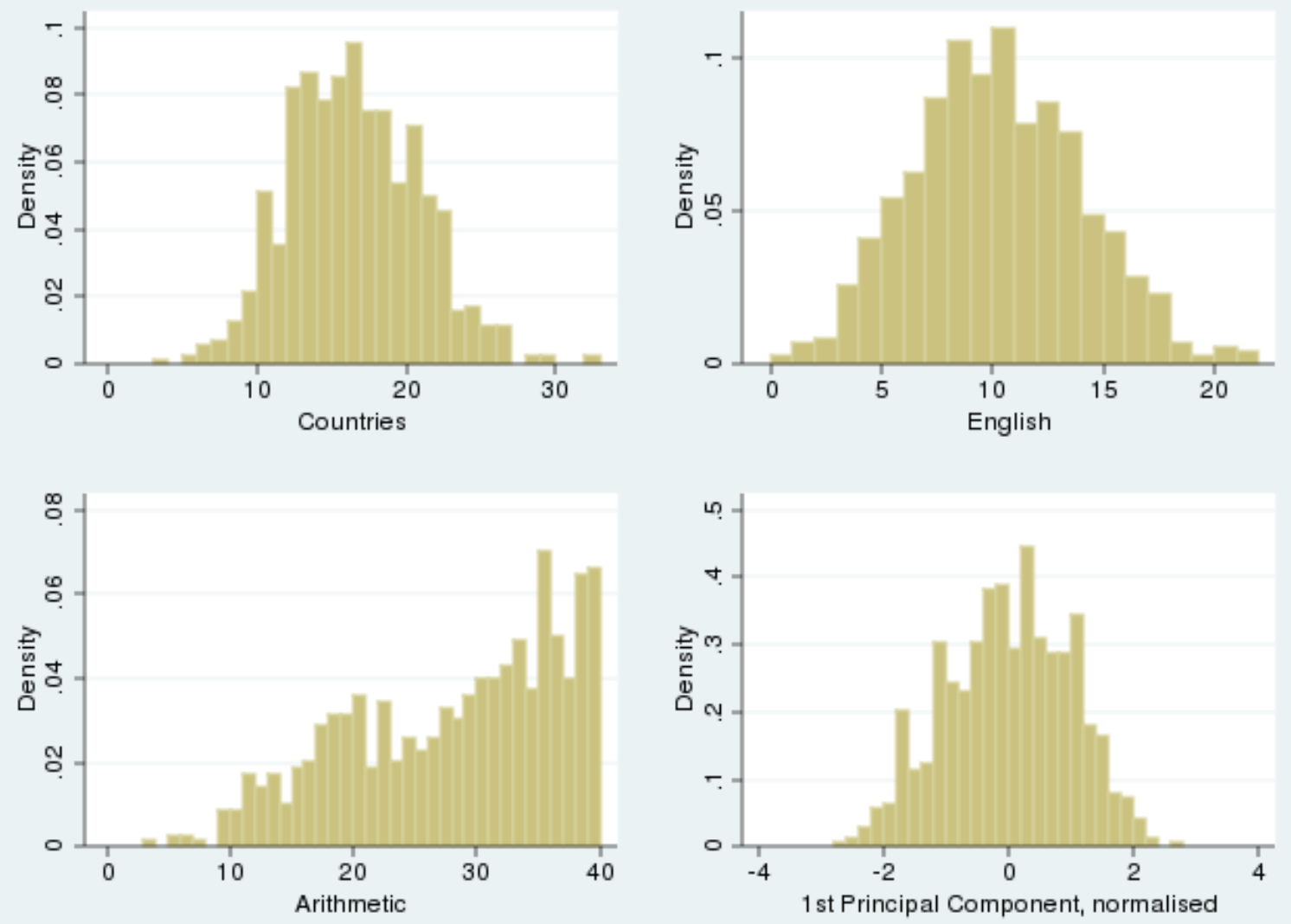
Figure A3 Test for Arithmetic

Time allowed: 4 minutes. $/$ समय: 4 मिनट

Solve as many as you can. Calculators are not allowed.

आप जितने अधिक प्रश्न हल कर सकते हों, करें। कैलकुलेटर के प्रयोग की अनुमति नहीं है।

\begin{tabular}{|c|c|c|c|}
\hline $16+25$ & $=$ & $632+244$ & $=$ \\
\hline $14+87$ & $=$ & $522-245$ & - \\
\hline $34-15$ & $=$ & $366+241$ & $=$ \\
\hline $43-17$ & $=$ & $753-283$ & $=$ \\
\hline $87-53$ & $=$ & $279+245$ & $=$ \\
\hline $62+52$ & $=$ & $846-639$ & $=$ \\
\hline $42-29$ & $=$ & $247+473$ & $=$ \\
\hline $59+31$ & $=$ & $472-183$ & $=$ \\
\hline $32+17$ & $=$ & $652+573$ & $=$ \\
\hline $87-74$ & $=$ & $470-265$ & $=$ \\
\hline $18: 3$ & $=$ & $42 * 11$ & $=$ \\
\hline $6 * 7$ & $=$ & $22 * 7$ & $=$ \\
\hline $80: 5$ & $=$ & $240: 15$ & $=$ \\
\hline $4^{*} 13$ & $=$ & $492: 12$ & $=$ \\
\hline $5 * 13$ & $=$ & $37 * 21$ & $=$ \\
\hline $52: 4$ & $=$ & $44 * 52$ & $=$ \\
\hline $23 \times 3$ & $=$ & $861: 3$ & $=$ \\
\hline $96: 4$ & $=$ & $536: 8$ & $=$ \\
\hline $66: 3$ & $=$ & $27 * 67$ & $=$ \\
\hline $43 * 3$ & $=$ & $72 * 86$ & $=$ \\
\hline
\end{tabular}

Notes: The actual size of the test was A4. 


\section{Figure A4 Sample page of the DCE}

1) Please consider the following job opportunities:/कृपया निम्नलिखित नौकरी के अवसरों पर विचार करें:

\begin{tabular}{|l|l|}
\hline & \multicolumn{1}{|c|}{ Job A } \\
\hline $\begin{array}{l}\text { Pay } \\
\text { वेतन }\end{array}$ & $\begin{array}{l}\text { Rs. 17000 per month } \\
17000 \text { रुपए प्रतिमाह }\end{array}$ \\
\hline $\begin{array}{l}\text { Location } \\
\text { स्थान }\end{array}$ & $\begin{array}{l}\text { Your home village / town } \\
\text { आपका गांव / कस्बा }\end{array}$ \\
\hline $\begin{array}{l}\text { Contract } \\
\text { नौकरी का अनुबंध }\end{array}$ & $\begin{array}{l}\text { Permanent, possibility to transfer after 7 years } \\
\text { स्थाई, और 7 वर्ष बाद स्थानातंरण की संभावना }\end{array}$ \\
\hline $\begin{array}{l}\text { Transfers } \\
\text { स्थानांतरण }\end{array}$ & $\begin{array}{l}\text { Depend on connections and influence } \\
\text { सिफारिश और पहुंच पर आधारित }\end{array}$ \\
\hline $\begin{array}{l}\text { Staff and pupils } \\
\text { स्टाफ और छात्रों की संख्या }\end{array}$ & $\begin{array}{l}\text { 2 teachers, 75 pupils } \\
2 \text { शिक्षक, 75 छात्र }\end{array}$ \\
\hline
\end{tabular}

\begin{tabular}{|l|l}
\hline & \multicolumn{1}{c}{ Job B } \\
\hline $\begin{array}{l}\text { Pay } \\
\text { वेतन }\end{array}$ & $\begin{array}{l}\text { Rs. 21000 per month } \\
21000 \text { रुपए प्रतिमाह }\end{array}$ \\
\hline $\begin{array}{l}\text { Location } \\
\text { स्थान }\end{array}$ & $\begin{array}{l}\text { Remote village } \\
\text { कोई दूरस्थ गांव }\end{array}$ \\
\hline $\begin{array}{l}\text { Contract } \\
\text { नौकरी का अनुबंध }\end{array}$ & $\begin{array}{l}\text { Fixed term contract, renewable every 7 years } \\
\text { निश्चित अवधि का अनुबंध, जिसका हर 7 वर्ष बाद नवीकरण किया जा सकता ह }\end{array}$ \\
\hline $\begin{array}{l}\text { Transfers } \\
\text { स्थानांतरण }\end{array}$ & $\begin{array}{l}\text { Depend on connections and influence } \\
\text { सिफारिश और पहुंच पर आधारित }\end{array}$ \\
\hline $\begin{array}{l}\text { Staff and pupils } \\
\text { स्टाफ और छात्रों की संख्या }\end{array}$ & $\begin{array}{l}\text { 2 teachers, 14 pupils } \\
2 \text { शिक्षक, 14 छात्र }\end{array}$ \\
\hline
\end{tabular}

\section{Given a choice, which of the above opportunities would you choose? Please circle:}

\section{Job A / Job B}

यदि आपको अपनी पसंद चुनने का विकल्प दिया जाए, तो ऊपर दिए गए अवसरों में से आप किसे चुनेंगे? कुपया नीचे अपनी पसंद पर गोले का निशान लगाएं:

\section{नौकरी $\mathrm{A}$ / नौकरी $\mathrm{B}$}

Notes: The actual size of the page was A4. 


\section{How Uttarakhand differs from other Indian States}

It is of interest whether the relationship between normal and para-teachers in Uttarakhand is typical or atypical in the context of India. Below, Figure A5 displays how normal and parateachers differ in terms of education, age and gender by district and the proportion of parateachers in the district's primary schools. It is recognised that the definition of a para-teacher varies somewhat per state and that the figures relate to teachers currently in the field, whereas our sample covers teachers early in their careers.

\section{Figure A5. The differences in education, age and gender between normal teachers and para-teachers across Indian districts}
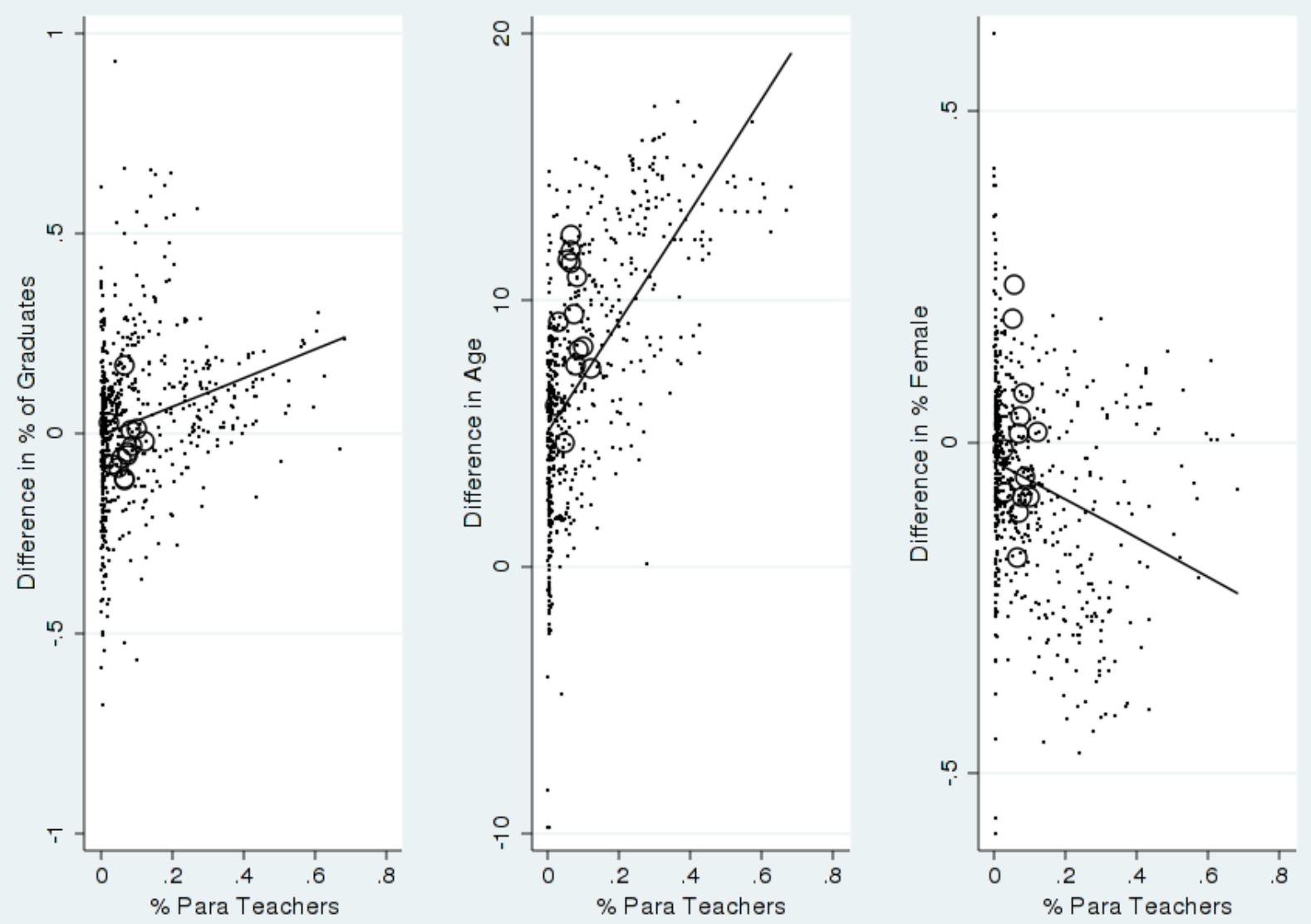

Notes: Source: DISE 2008-09 teacher database. Circles refer to districts of Uttarakhand and the dots to other Indian districts. The $\mathrm{X}$-axis displays the proportion of primary school teachers that are para-teachers in the district. The Y-axis displays the difference in the average characteristics between the two teacher types in each district (for example, in the middle figure, 10 would imply that permanent teachers are on average 10 years older than para-teachers). The line depicts an OLS regression line of Y on X.

The first panel of Figure A5 shows that in general, the larger the share of para-teachers in state primary schools, the more educated the normal teachers are in relation to parateachers. The line in the figure is an OLS regression line for the two variables. The second panel shows that the more para-teachers the district uses, the younger the para-teachers tend to be in relation to normal teachers. Finally, the last panel suggests that para-teachers are more often female, and increasingly so if larger proportion of the district's teachers are para-teacher. 
Although, in the last case, the correlation between the variables in weaker than in the first two panels.

In Figure A5, all 13 districts of Uttarakhand are denoted with circles, instead of dots. As discussed earlier, approximately $8 \%$ of Uttarakhand's primary school teachers are parateachers, which is fairly 'middle-of-the-pack' figure for India as a whole. The variation in the differences between the characteristics of para and regular teachers across Uttarakhand's districts is fairly large, as evidenced by Figure A5. Overall, one can safely conclude that Uttarakhand is by no means an outlier state in relation to how much it has relied on parateachers and how much its para-teachers differ from regular teachers within the districts. 


\section{BIS Department tor Business

\section{Spatial Economics Research Centre (SERC)}

London School of Economics

Houghton Street

London WC2A 2AE

Tel: 02078523565

Fax: 02079556848

Web: www.spatialeconomics.ac.uk

SERC is an independent research centre funded by the Economic and Social Research Council (ESRC), Department for Business Innovation and Skills (BIS), the Department for Communities and Local Government (CLG) and the Welsh Assembly Government. 